NBER WORKING PAPER SERIES

\title{
MATERNAL MORTALITY RISK AND SPOUSAL DIFFERENCES IN THE DEMAND FOR CHILDREN
}

\author{
Nava Ashraf \\ Erica M. Field \\ Alessandra Voena \\ Roberta Ziparo \\ Working Paper 28220 \\ http://www.nber.org/papers/w28220 \\ NATIONAL BUREAU OF ECONOMIC RESEARCH \\ 100 Massachusetts Avenue \\ Cambridge, MA 0213 \\ December 2020, Revised July 2021
}

We thank Laura Argys, Jean-Marie Baland, Dan Bennett, Renaud Bourlès, Leonardo Bursz-tyn, Matthias Doepke, Marcel Fafchamps, Matt Gentzkow, Emir Kamenica, Corinne Low, Rachel Heath, Shelly Lundberg, Gautam Rao, Michèle Tertilt, and Christine Valente for helpful comments. We thank Dr. Ruben Mbewe, Dr. Chomba Nambao, Dr. Caroline Phiri, Ms. Jully Chilambwe, Ms. Hilda Wina and the staff at Chipata and Chaisa clinic for their support to the project. Federica Esu and Sonakshi Sharma were essential contributors to the field implementation of the study. We are also grateful to Conceptor Chilopa, Aleta Haflett, Milambo Mavumba, Grace Msichili, Jessica Pettit and Sindy Yiu for their support in the field. Ruchi Mahadeshwar, Maria Alejandra Rodriguez Vega, Kim Sarnoff, Nicholas Swanson and Tianyu Zheng provided excellent research assistance. Funding for this research was provided in part by the Global Development Network/International Initiative for Impact Evaluation, the International Growth Centre, the John Templeton Foundation, BERI/CEGA, the William and Flora Hewlett Foundation, the Becker Friedman Institute and an anonymous donor. The study was approved by the Biomedical Research Ethics Committee at University of Zambia (UNZABREC-016-03-12) and by the Institutional Review Board at the University of Chicago (IRB13-0316). The study is registered on the AEA RCT registry (AEARCTR-0000022). Voena thanks the Sustainability Science program at the Harvard Kennedy School and the Sloan Foundation for a Research Fellowship. The opinions expressed in this manuscript are those of the authors and do not necessarily reflect the view of the sponsors or the National Bureau of Economic Research.

NBER working papers are circulated for discussion and comment purposes. They have not been peer-reviewed or been subject to the review by the NBER Board of Directors that accompanies official NBER publications.

(C) 2020 by Nava Ashraf, Erica M. Field, Alessandra Voena, and Roberta Ziparo. All rights reserved. Short sections of text, not to exceed two paragraphs, may be quoted without explicit permission provided that full credit, including (C) notice, is given to the source. 
Maternal Mortality Risk and Spousal Differences in the Demand for Children

Nava Ashraf, Erica M. Field, Alessandra Voena, and Roberta Ziparo

NBER Working Paper No. 28220

December 2020, Revised July 2021

JEL No. J11,J13

\begin{abstract}
$\underline{\text { ABSTRACT }}$
Fertility decisions are often made by partners who may disagree. We develop a model in which conflicting interests prevent effective communication between spouses about the costs of childbearing incurred by women. This mechanism is likely to further widen the spousal disagreement over fertility in environments where maternal health risk is high and imperfectly observed. We design an intervention to experimentally vary exposure to information about maternal health costs to either the husband or the wife among approximately 500 couples in Lusaka, Zambia. At baseline, husbands exhibit lower knowledge of maternal health risk compared to their wives. One year after the intervention, husbands significantly update their beliefs about maternal risk but only if the information is delivered directly to them, whereas wives update their beliefs about risk regardless of who in the household is treated. The intra-household asymmetry in information spillovers is strongest among men with more urgent demand for children. Households treated with information on maternal risk experience a sizable reduction in the probability of pregnancy an effect which is strongest when the woman faces a higher risk of complications - but only when the information is delivered to wives rather than husbands is this decline in fertility accompanied by a significant reduction in transfers to the wife. These patterns are consistent with differences in initial beliefs and demand for children generating a barrier to credible communication between spouses.
\end{abstract}

Nava Ashraf

Department of Economics

London School of Economics

Houghton Street

London WC2A $2 \mathrm{AE}$

United Kingdom

n.ashraf1@1se.ac.uk

Erica M. Field

Department of Economics

Duke University

Social Sciences Building

Box 90097

Durham, NC 27708

and CEPR

and also NBER

emf23@duke.edu

\author{
Alessandra Voena \\ Stanford University \\ Landau Economics Building \\ 579 Jane Stanford Way \\ Stanford, CA 94305 \\ and NBER \\ avoena@stanford.edu
}

Roberta Ziparo

Aix-Marseille Université

5-9 Boulevard Bourdet, CS 50498

13205 Marseille Cedex 1

France

roberta.ziparo@univ-amu.fr

A online appendix is available at http://www.nber.org/data-appendix/w28220 
Fertility decisions, like many other high-stakes economic choices, are more often made at the household rather than the individual level. Agents within a household may disagree, but different preferences and incentives do not necessarily lead to inefficient outcomes: a joint optimum can often be achieved through a compensating transfer. In some cases, however, when spouses have significantly different private optima, it may be difficult to reach efficient household outcomes (Ashraf, Field and Lee, 2014; Doepke and Kindermann, 2019). As we illustrate in this paper, one reason this may happen is simply because spouses do not always have access to the same information about childbearing, and hence might hold systematically different beliefs about the costs and benefits of fertility choices over number and spacing of children. While communication between partners is generally expected to generate convergence in beliefs, diverging interests may impede the flow of information within the household, leading to fertility outcomes that depart from the joint optimum.

In this paper, we explore the role of information asymmetries and barriers to credible communication in shaping household decision-making over fertility. In particular, we examine spouses' knowledge of maternal health risk, how it spreads between partners, and how it influences gender differences in the demand for children and household fertility outcomes. Our study takes place in Lusaka, Zambia, where married men on average report high desired fertility, both in absolute terms and relative to women, as is also seen across Sub-Saharan Africa (Westoff, 2010). Zambia also has one of the world's highest maternal mortality ratios, amounting to a lifetime risk of maternal death of one woman in 59 (Central Statistical Office, 2014).

We first document a significant gender gap in reproductive health risk awareness, which we argue stems from the gendered spheres of direct and indirect knowledge accumulation of maternal labor and delivery outcomes that typifies much of the developing world. We collect novel data on beliefs about maternal health costs, which reveal that husbands in poor peri-urban Lusaka have limited knowledge, compared to their wives, of the risk factors that influence childbirth outcomes. This observation alone raises two immediate questions: what allows members of the same household to maintain systematically different beliefs about maternal health risk, and to what extent does this gender gap in knowledge influence fertility?

To make sense of this stylized fact, we develop a theoretical model that explores information transmission and fertility decisions in the household when couples may differ with respect to both their knowledge of childbearing risk, their ex ante preferences over optimal number of children, 
the utility cost they assign to maternal mortality and morbidity, and their biological control over fertility. Without information asymmetries, spousal cooperation ensures efficient levels of fertility as long as there is potential to make intrahousehold transfers. However, the model demonstrates that gender differences in fertility preferences and costs can introduce a barrier to information sharing, generally from women to their husbands, that prevents convergence in beliefs about maternal health risk within couples. In this manner, information asymmetries on childbearing costs within couples can result in a persistent wedge between male and female demand for children that is not resolved with transfers. Hence, asymmetries of information about maternal health risk are a potentially important determinant of household fertility: when women are better informed than men about risk, households are unable to implement optimal contracts over fertility, reducing transfers from husbands to wives and leading to sub-optimal fertility outcomes.

We test the predictions of the model through a field experiment with over 500 couples, delivering information on maternal health risk to husbands and wives and randomizing the identity of the recipient within each participating couple. Consistent with our model's predictions, husbands significantly update their beliefs about maternal risk factors only if the information is delivered directly to them. Meanwhile, wives update their beliefs about maternal risk regardless of whether they or their husband receives the information. This gender asymmetry alone indicates the presence of critical barriers to female-to-male communication about risk. Consistent with this interpretation, treated husbands - but not treated wives - report higher levels of communication with their spouse about family planning, and higher relationship satisfaction.

Furthermore, all households treated with information on maternal risk experience a sizable reduction in the incidence of pregnancy over the year following treatment, a reduction which is strongest when the woman faces a higher risk of complications based on her birth history. In particular, households in which the husband is treated experience a $43 \%$ reduction in the probability of having a child or being pregnant in the year following the intervention. When the information is delivered to wives rather than husbands, the decline in fertility is accompanied by a significant reduction in transfers from the husband to the wife. This combination of results is consistent with women updating their awareness of maternal risk while being unable to convey that effectively to their partner.

The patterns with respect to demand for children are also consistent with our theoretical 
model of communication barriers. The asymmetry in knowledge spillovers is driven by households in which husbands, at baseline, want a child as soon as possible. In our model, these households are the most likely to experience a conflict of interest. In the data, these men do not update their beliefs in response to their wife's treatment status, and reduce transfers to their wife more than other groups when she is treated. Likewise, when wives are treated, fertility declines are concentrated among households in which the husband has relatively low demand for children, precisely those in which communication barriers are expected to be minimal in our model. Indeed, when a husband wants a child as soon as possible, treating his wife has no effect on fertility. These findings, together with those on transfers, suggest that strategic communication concerns, and not simply a generically lower propensity among men to incorporate information heard from women, limit informative communication from women to men.

Beyond uncovering central barriers to optimal decision-making over family planning that are likely to be relevant in many high fertility settings, a central contribution of our paper is to study the diffusion of information within the household and its long-term consequences. In the context of maternal mortality, we show that information asymmetries within households may persist as equilibrium outcomes, and thereby influence the ability of public health campaigns to change household outcomes.

While the vast literature on household decision-making assumes that household members have access to the same information, and that new information spreads seamlessly within the family (Chiappori, 1992; Lundberg and Pollak, 1996; Bourguignon et al., 1993), a smaller body of literature has examined the degree to which asymmetric information between spouses affects household decision-making (see de Laat (2005); Ashraf (2009); Stern and Friedberg (2010); Chen (2013); Baseler (2020)). This paper contributes to a novel body of recent work that has started to explore the transmission of information within the household (Ziparo, 2020; Apedo-Amah, Djebbari and Ziparo, 2020; Conlon et al., 2021), and it is the first, to our knowledge, to study its implications for real-life decisions, such as fertility.

By providing evidence on both direct and spillover effects of information on behavior, our paper also contributes more generally to understanding the role of information for economic behavior. A rich body of evidence has shown that information can have a substantial impact, through a process of beliefs updating or by enhancing salience, on educational choices in developing countries (Jensen, 2010; Dizon-Ross, 2019) and on health outcomes (see, among others, 
Thornton (2008); Dupas (2011); De Paula, Shapira and Todd (2014); Delavande and Kohler (2016); Bennett, Naqvi and Schmidt (2018)). We contribute to this literature by highlighting that targeting particular household members may affect household behavioral responses to new information, just as in the case of cash transfers (Lundberg, Pollak and Wales, 1997; Attanasio and Lechene, 2002; Duflo, 2003). If information flows between spouses are constrained, it is particularly important who in the household public health messages target. In our setting, there is a strong policy argument for targeting men with information related to reproductive health, a domain in which women are systematically more informed and where men are not commonly addressed by information campaigns.

Measuring information spillovers and diffusion within the household sheds light on motivations for information sharing and influencing joint decisions in group settings. While the effect of preference misalignment on communication has been studied in the lab, our empirical application provides the first field experimental evidence that directly tests models of strategic communication, wherein persistent differences in preferences and conflict of interest impede communication and beliefs updating (Crawford and Sobel, 1982; Mailath, 1987; Crawford, 1998, 2019). ${ }^{1}$

Our study also contributes to the literature on decision-making over fertility when spouses have different preferences and incentives. ${ }^{2}$ By examining the role of beliefs about maternal mortality risk, we contribute to the literature on determinants of fertility decisions, especially in terms of expectations, including the work by Rosenzweig and Schultz (1982) on child mortality in Colombia and by Albanesi and Olivetti (2014) on maternal mortality in US history. We emphasize that initial differences in ideal fertility between men and women, which are large across sub-Saharan Africa and in Zambia (see figure 1 panel a), can generate persistent and systematic disagreement over the demand for children (panel b).

Finally, these findings inform the policy debate on male involvement in family planning.

\footnotetext{
${ }^{1}$ See, for instance, Dickhaut, McCabe and Mukherji (1995) and Cai and Wang (2006) test the model of Crawford and Sobel (1982) in a laboratory setup, while Dickson, Hafer and Landa (2008) show responsiveness of communication to strategic incentives in a committee voting laboratory experiment.

${ }^{2}$ While the sociology and demography literature studying spouses' interactions on fertility decisions is well established, few studies in economics have emphasized the role of intra-household interactions (Rasul (2008); Ashraf, Field and Lee (2014); Doepke and Kindermann (2019) and Rossi (2019)) and culture (Fernandez and Fogli, 2009) in this process. Outside of economics, see studies about fertility and contraceptives use from a theoretical perspective (Blanc, 2001; Miller, Severy and Pasta, 2004; Brehm and Schneider, 2019), in developed countries (Bauer and Kneip, 2012; Stein, Willen and Pavetic, 2014), and in Sub-Saharan Africa (Ezeh, 1993; Bond and Dover, 1997; Dodoo, 1998; DeRose et al., 2004; Pulerwitz et al., 2010; Gottert et al., 2018).
} 
Figure 1: Spousal Disagreement in Ideal Fertility in Sub-Saharan Africa

(a) Difference in Reported Ideal Fertility between Husband and Wife

(b) Fraction of Couples that Disagrees over Having An-

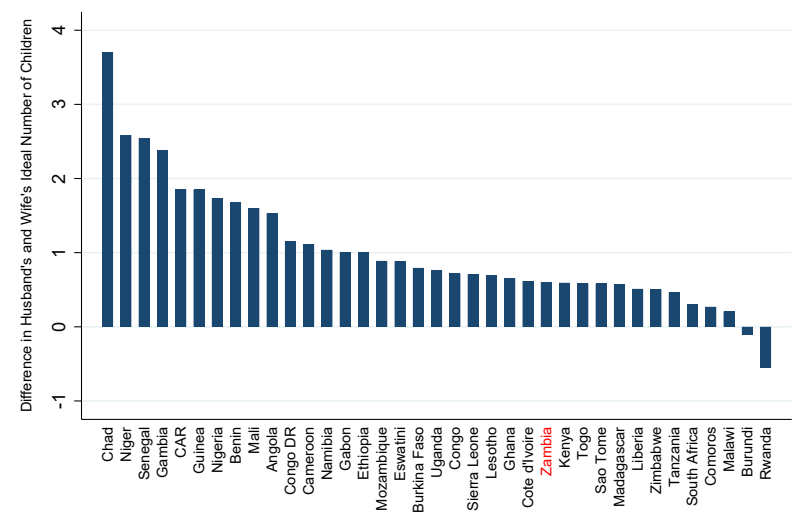
other Child

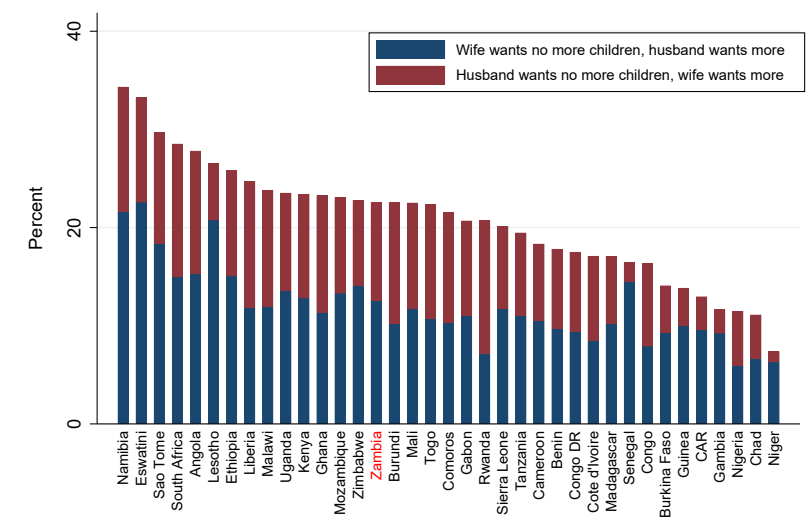

Notes: Data from the most recent waves of Demographic and Health Surveys. Polygamous couples are excluded from each sample for which such information is available.

While several studies have highlighted men's central role in reproductive health decision making (Vouking, Evina and Tadenfok, 2014), studies often find no effect of male-targeted family planning campaigns, or even negative ones (Ashraf, Field and Lee, 2014). ${ }^{3}$ Our results indicate that involving men in reproductive health can be an effective tool to reduce unmet need for family planning, when interventions can fill specific intra-household gaps in communication. Indeed, we find that the reduction in fertility that we experimentally induce by providing information to men is not inferior to the one generated by the information to women. The effect we document is of the same order of magnitude of other household-level interventions which have been shown to reduce pregnancy such as Ashraf, Field and Lee (2014). However, unlike the latter study, this effect is accompanied, only when the husband is treated, by an improvement in the marital surplus, instead of a worsening, as measured by greater marital satisfaction, communication, and closeness. As reducing unmet need for family planning in Sub-Saharan Africa becomes an increasingly important policy goal, finding strategies to decrease excess male demand for children while enhancing family unity, rather than exacerbating existing conflict within the household, will be critical.

\footnotetext{
${ }^{3}$ Although some randomized public health studies found that providing contraceptive education to husbands may increase uptake of modern contraceptives (Wang et al., 1998; Terefe and Larson, 1983; Fisek and Sumbuloglu, 1978), one large study found no effect (Freedman and Takeshita, 1969). Recent evidence from rural Malawi and Tanzania suggests that promoting contraceptive use among men has the potential to substantially increase takeup (Shattuck et al., 2011; McCarthy, 2019; Miller, De Paula and Valente, 2020).
} 


\section{Context}

We conducted this study in Lusaka, the capital city of Zambia. High fertility rates in Lusaka, coupled with rapid rural-to-urban migration, has led to the establishment of informal settlements (or compounds), in which a growing proportion of the city's population resides. ${ }^{4}$ Our study took place in some of these communities. In this section, we describe the reproductive health challenges in Zambia more generally and in our sample from the compounds of Lusaka.

\subsection{Fertility, desired fertility and contraceptive use}

Zambian fertility rates are high. Data from the 2014 DHS indicate that the total fertility rate in Zambia is 5.3 children per woman aged 15-49, one child below the total fertility rate measured in the 1992 DHS. Urban areas have a somewhat lower rate, at 3.7 children per woman.

High fertility in Zambia is associated with a high unmet need for family planning services: $14 \%$ of married women report having an unmet need for spacing births and an additional $7 \%$ report an unmet need for limiting them. Nevertheless, desired fertility is also high and it differs significantly between married men and married women: in the 2014 DHS, the ideal number of children is 5.1 for married women and 5.7 for married men nationwide. Figure 2 highlights the discrepancy in the desire for additional children as a function of the current number of living children in that sample (panel a).

From our baseline survey, collected in the Fall of 2014 on 715 couples in peri-urban Lusaka and partially overlapping with our study sample, similar patterns emerge. Ours is a prime-age urban sample, and the average age for women is 28. Yet, women in the sample have on average 2.6 children (table 1, panel A). ${ }^{5}$ Unmet need for family planning is high. Overall, $32 \%$ of the women in our sample report not using modern contraceptives at baseline. Of the $33 \%$ of women in our sample who want no more children, $27 \%$ are not using any modern contraceptive (8\% of our overall sample). Similarly, of the $52 \%$ women in our sample who wish to delay giving birth by at least one year, $23 \%$ are not using any modern contraceptive (12\% of our sample in total).

As observed in the nationally-representative sample from the DHS, men in our sample have higher desired fertility on average than their wives: 4.43 for men, 4.19 for women (table 1,

\footnotetext{
${ }^{4}$ According to the World Bank, 43\% of the Zambian population in 2017 resided in urban cities. Data available at https://data.worldbank.org/indicator/sp.urb.totl.in.zs, last accessed May 2019.

${ }^{5}$ Women aged 35 and above (16\% of our sample), and hence closer to completed fertility, have on average 3.9 children.
} 
Figure 2: Percent that Want No More Children by Current Number of Children in the DHS and in the Baseline Survey

(a) DHS

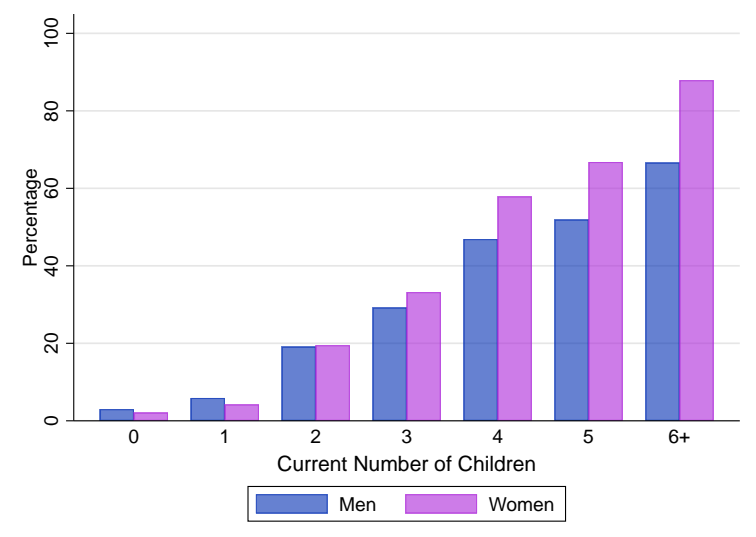

(b) Baseline Survey

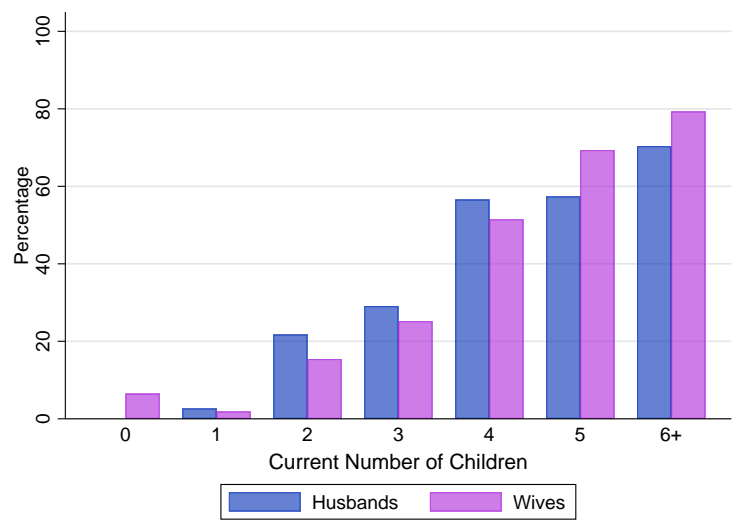

Notes: Left-hand side bar graph summarizes percentages of men and women for DHS 2013-2014 data; right-hand side bar graph summarizes percentages of husbands and wives in our sample.

panel A). Indeed, the distribution of men's reported ideal fertility first order stochastically dominates that of women (see Appendix figure A1, panel b). In $35.7 \%$ of couples, there is no gap between husband and wife in ideal number of children. In $36.6 \%$ of couples, the husband wants more children than the wife (on average 1.9 more children). In the remaining $27.7 \%$, the wife wants more children than the husband (on average 1.6 more children). Nevertheless, given the particular age distribution in our sample, men tend to have more children than their wives because of prior relationships, attenuating the potential disagreement over whether to have more children.

In our sample, men and women also exhibit substantial differences in their attitudes towards family planning and contraception. For instance, $38.3 \%$ of men report thinking that contraceptives are bad for a woman's health, against $17.2 \%$ of women (table 1, panel A). Similarly, 31.0\% of men report thinking that contraceptives reduce a woman's future ability to conceive, against $17.0 \%$ of women. In addition, $57.9 \%$ of men report thinking that contraceptives enable women to be unfaithful, against $37.6 \%$ of women.

\subsection{Knowledge, beliefs and communication about maternal health risk}

According to the 2014 DHS, the maternal mortality ratio in Zambia is equal to 398 deaths per 100,000 live births. Given the high rates of fertility in the country, this ratio implies that, 
Table 1: Fertility Outcomes, Preferences, Beliefs and Attitudes at Baseline

\begin{tabular}{|c|c|c|c|c|}
\hline & Women & Men & Diff. SE & p-value \\
\hline \multicolumn{5}{|l|}{ Panel A: Fertility and Family Planning } \\
\hline Living children & 2.598 & 2.890 & $(0.089)$ & {$[0.001]$} \\
\hline Ideal number of children & 4.188 & 4.426 & $(0.082)$ & {$[0.004]$} \\
\hline Likelihood of having another child & 6.490 & 6.171 & $(0.192)$ & {$[0.096]$} \\
\hline Want another child (dummy) & 0.714 & 0.658 & $(0.026)$ & {$[0.028]$} \\
\hline Diff in ideal and current number of children & 1.584 & 1.553 & $(0.084)$ & {$[0.716]$} \\
\hline Fraction contrac. methods believed to be bad for health & 0.172 & 0.383 & $(0.013)$ & {$[0.000]$} \\
\hline Fraction contrac. methods believed to lower fecundity & 0.170 & 0.310 & $(0.013)$ & {$[0.000]$} \\
\hline Agrees that contrac. help women be unfaithful & 0.376 & 0.579 & $(0.026)$ & {$[0.000]$} \\
\hline \multicolumn{5}{|l|}{ Panel B: Maternal Mortality and Morbidity } \\
\hline Ideal space between children $(\mathrm{m})$ & 41.142 & 36.636 & $(0.955)$ & {$[0.000]$} \\
\hline Months woman should give body to recover post-birthing & 27.058 & 26.132 & $(0.975)$ & {$[0.343]$} \\
\hline Women with more kids at higher risk of complications & 0.777 & 0.720 & $(0.023)$ & [0.013] \\
\hline Older women at higher risk of complications & 0.846 & 0.743 & $(0.021)$ & {$[0.000]$} \\
\hline Likelihood of complications if immediately pregnant & 8.000 & 7.880 & $(0.127)$ & {$[0.343]$} \\
\hline Likelihood of complications if pregnant 12 months after delivery & 4.722 & 4.686 & $(0.137)$ & [0.793] \\
\hline Likelihood of complications if pregnant 24 months after delivery & 2.400 & 2.155 & $(0.124)$ & {$[0.048]$} \\
\hline Likelihood of complications if less than 4 kids & 3.076 & 2.933 & $(0.121)$ & [0.238] \\
\hline Likelihood of complications if more than 4 kids & 5.805 & 6.014 & $(0.136)$ & [0.123] \\
\hline Likelihood of complications if younger than 40 & 3.721 & 3.261 & $(0.130)$ & {$[0.000]$} \\
\hline lications if older than 40 & 7.930 & 7.451 & $(0.118)$ & {$[0.000]$} \\
\hline Reports that infidelity increases risk of complications & 0.420 & 0.555 & $(0.026)$ & {$[0.000]$} \\
\hline Relative infidelity weight & 0.304 & 0.328 & $(0.009)$ & {$[0.009]$} \\
\hline \multicolumn{5}{|c|}{ Panel C: Maternal Complications Experience and Communication } \\
\hline Past maternal and birth complications or difficulties & 0.138 & 0.175 & $(0.019)$ & {$[0.055]$} \\
\hline Past maternal complications or difficulties & 0.113 & 0.114 & $(0.017)$ & {$[0.918]$} \\
\hline Immediate family member died from complications & 0.039 & 0.032 & $(0.010)$ & {$[0.470]$} \\
\hline Close relative died from complications & 0.067 & 0.049 & $(0.012)$ & {$[0.147]$} \\
\hline Close friend died from complications & 0.110 & 0.068 & $(0.015)$ & {$[0.006]$} \\
\hline Distant friend died from complications & 0.108 & 0.050 & $(0.014)$ & {$[0.000]$} \\
\hline Communicated info about future possibility of complications & 0.534 & 0.276 & $(0.025)$ & {$[0.000]$} \\
\hline Observations & 714 & 714 & & \\
\hline
\end{tabular}

Notes: Baseline survey collected in the Fall of 2014. "Likelihood of complications..." variables is the reported likelihood on a scale from 0 to 10 (question wording reported in the Appendix). "Relative infidelity weight" is the percentage of points assigned to infidelity as a cause for maternal mortality as opposed to health problems or lack of healthcare. Wording of all questions in Appendix D.

in expectation, 1 in 59 Zambian women dies giving birth (Central Statistical Office, 2014).

The primary causes of maternal death in Zambia are obstructed labor, hemorrhage, blood pressure disorders and sepsis (Banda, 2015). The high incidence of maternal mortality implies a correspondingly high incidence of severe maternal morbidity in the general population, which is typically believed to be orders of magnitude larger than maternal mortality. ${ }^{6}$ Data on maternal

\footnotetext{
${ }^{6}$ Maternal morbidity is defined as unexpected outcomes of labor and delivery that result in significant consequences to a woman's health. According to the WHO, for every woman who dies in childbirth, 20 or 30 experience acute or chronic morbidity. Across Sub-Saharan Africa, for example, the range of instances of severe morbidity over 1,000 births is estimated between 109 for Nigeria and 9 for Tanzania, hence tens of times higher
} 
morbidity, however, is not systematically available for Zambia nor in other comparable contexts. ${ }^{7}$

Our survey provides unique insights into men's and women's knowledge of maternal health risk. Men are less likely than women to identify high parity (72.0\% of men and $77.7 \%$ of women) and advanced maternal age (74.3\% of men and $84.6 \%$ of women) as risk factors (table 1 , panel B). In a sequence of questions in which respondents are asked to report the likelihood, on a scale from 0 to 10, that a hypothetical woman with given set characteristics (age, parity, most recent birth) may experience complications at birth, men report lower scores than women in six out of

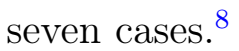

As documented in Ashraf et al. (2017), in Zambia, common perceptions of the causes of maternal mortality are influenced by deeply-rooted traditional beliefs widespread also in other parts of Sub-Saharan Africa. In particular, marital infidelity by either spouse is considered a primary cause of maternal health complications, (Nsemukila et al., 1999; Umoiyoho et al., 2005; Garenne et al., 1997; Gennaro et al., 1998), often discouraging women from seeking medical help when complications arise (Phiri et al., 2014). Indeed, $55.5 \%$ of men and $42.0 \%$ of women report (without prompting) infidelity as a leading cause of maternal labor and delivery complications, assigning to it greater weight as a root cause of maternal mortality than lack of appropriate healthcare and poor health status combined. ${ }^{9}$ The stigma arising from this belief is highly relevant to information transmission within the household on maternal risk, because it potentially reduces women's willingness to raise concerns about birth complications with her spouse.

When asked about the wife's direct experience with complications and difficulties at birth, men and women have very similar propensity to report experiencing birth complications $(11.4 \%$ of men and $11.3 \%$ of women). ${ }^{10}$ The majority of adverse events reported by men and women in our sample involve hemorrhages, c-sections, breech presentations, obstructed or prolonged labor, and tearing. Similarly, reported exposure to maternal mortality episodes within the community is similar for women and men when immediate family members or close family members are than mortality, see Geller et al. (2018).

${ }^{7}$ The exception is the Global Network Maternal and Newborn Health (MNH) Registry Data from 2014 and 2016, that places the ratio of extremely severe morbidity ("near miss") to mortality at 19:1 (Goldenberg et al., 2017). Such an incidence would place the lifetime risk of death or near miss to over $40 \%$.

${ }^{8}$ See Appendix D1 for the wording of the relevant question.

${ }^{9}$ To elicit the weight that respondents attribute to different causes, we gave respondents 30 buttons and asked them to allocate between causes. See the Appendix for the wording of the questions.

${ }^{10} \mathrm{In}$ fact, men are more likely than women to report that any complication occurred $(17.5 \%$ of men and $13.8 \%$ of women, table 1, panel C). However, this is only because men are substantially more likely to report miscarriages and stillbirths as maternal health complications. Without these events, the rates are almost identical $(11.4 \%$ as reported by men and $11.3 \%$ as reported by women. 
concerned. However, reported incidence of maternal mortality differs substantially across male and female respondents as social distance to the victim increases. Only $6.8 \%$ of men report knowing a close friend whose wife has died giving birth, while $11.0 \%$ of women know a close friend who has died giving birth. An even greater gap is observed for distant friends (table 1, panel C). Despite this gap in experience, only $27.6 \%$ of men and $53.4 \%$ of women report having attempted to discuss maternal health risk with their spouse.

Finally, one factor that appears to influence communication about maternal mortality risk is men's desired fertility. Indeed, both husbands and wives in our survey report that communication on maternal health is significantly more likely to occur and to not break down when men no longer want children compared to when they want a child as soon as possible (Appendix table A1). This correlation motivates our theoretical setup and justifies exploring heterogeneity of treatment effects by the man's demand for children.

Overall, our data indicate that, while maternal health is a relevant source of concern for the couples in this setting, significant gaps in exposure to information and in the understanding of maternal health risk exist within the household.

\section{Model}

We construct a theoretical framework to examine how fertility decisions are made within the household, highlighting the role played by communication about maternal health cost. We first show that ex ante asymmetries of information on maternal health cost may break down the spousal agreement over fertility. Then, we study how an information intervention may affect communication and realized fertility, and discuss heterogeneity in the expected effects of the intervention.

\subsection{Environment}

Men and women make fertility decisions, given their preferences for children and the maternal health cost of fertility. We model these decisions within a static framework as completed fertility is realized only once in a couple.

Maternal health cost Maternal health cost is a random variable denoted as $\theta$. In Zambia, a high-cost environment, $\theta$ is distributed with probability density function (pdf) $f^{Z}(\theta)$ on the 
interval [0,1], with first and second moments equal to $\theta^{Z}$ and $\sigma^{Z}$ respectively. Worldwide, instead, $\theta$ has a pdf denoted as $f^{G}(\theta)$ on the interval $[0,1]$, with first and second moments equal to $\theta^{G}$ and $\sigma^{G}$ respectively. Because Zambia is a (relatively) high maternal health cost environment, we assume that $\theta^{Z}$ is sufficiently larger than $\theta^{G}$ (notably, that $\theta^{Z}>\frac{1+\theta^{G}}{2}$ ). ${ }^{11}$

To match the descriptive statistics in our baseline sample (see table 1, panel B and panel C), we assume that there exist two types of households:

i) the equally uninformed households, in which, prior to the intervention, neither the husband nor the wife observe the realization of $\theta$ and they both believe that the wife cost is drawn from the worldwide distribution (with mean $\theta^{G}$ );

ii) the asymmetrically informed households, in which the wife knows the cost realization $\theta_{j}$, while the husband does not observe the realization of the cost and believes the cost to be drawn from the worldwide distribution (with mean $\theta^{G}$ ).

Actions The woman can choose how many children to have $(n)$. She does so through a set of actions that encompass contraceptive use, frequency of sexual intercourse and investments in her health. The husband can offer transfers $t$ to influence the wife's actions, compensating her for fertility levels that depart from her private optimum.

Preferences People receive utility from their fertility and from transfers. Spouses have different preferences that depend on the realized number of children. In line with the literature (see for example Rossi (2019)), each spouse wants to minimize the distance between realized fertility and their net fertility objectives, which are determined by the difference between ideal fertility and the maternal health cost. ${ }^{12}$ Formally, spouses' preferences are the following:

$$
U_{j}^{H}=-\left(\alpha^{H}-\delta \theta_{j}-n\right)^{2}-\gamma t
$$

\footnotetext{
${ }^{11}$ Allowing for bias in our baseline model allows us to incorporate the evidence from our the baseline data, that suggests that men have systematically different beliefs compared to women, on average. In the Appendix,t we discuss the case in which uninformed spouses know the real cost distribution in Zambia (with mean $\theta^{Z}$ ). In such a case, uninformed agents are not biased. We present the effect of the intervention on intra-household interactions when either the husband or the wife is treated.

${ }^{12}$ We chose quadratic preferences in which the type enters linearly in the quadratic form because they are standard in the cheap-talk literature (since Crawford and Sobel, 1982) as they allow for closed form solutions of the partition equilibria. This particular functional form has the drawback of implying that the indirect utility of a spouse is increasing in the health cost as soon as the equilibrium number of children is higher than the ideal preferences. However, our results do not rely on this specific functional form. Results under alternative functional forms that do not have this implication are discussed in Appendix B.3.
} 


$$
U_{j}^{W}=-\left(\alpha^{W}-\theta_{j}-n\right)^{2}+t
$$

where $\alpha^{i}$ is each spouse's ideal fertility, $\theta_{j}$ is the realized maternal health cost, $n$ is the realized number of children in the household, $t \geq 0$ is the amount transferred by the man, $\gamma$ is the man's (finite) disutility of (monetary or in-kind) transfers, and $0 \leq \delta \leq 1$ captures the extent to which the husband internalizes the maternal health cost. ${ }^{13}$

To replicate the empirical distribution of ideal fertility, we introduce the following assumption:

Assumption 1. Couples are heterogeneous in term of the difference in ideal fertility $\alpha^{H}-\alpha^{W}$. The average difference is positive and increases as $\alpha^{H}$ increases.

This assumption reflects the strong positive correlation between the spouses' difference in ideal fertility and the ideal fertility of the husband observed in our data and in DHS data (figure A2). ${ }^{14}$ This correlation is expected to arise when the distribution of the ideal fertility of the husband first order stochastically dominates that of the wife and spouses match assortatively on preferences.

\subsection{Benchmark case: fertility under complete information}

We start by describing optimal fertility levels with complete information on maternal health cost. We define

$n_{j}^{H}=\operatorname{argmax}_{n}\left[-\left(\alpha^{H}-\delta \theta_{j}-n\right)^{2}\right]=\left(\alpha^{H}-\delta \theta_{j}\right) ; \quad n_{j}^{W}=\operatorname{argmax}_{n}\left[-\left(\alpha^{W}-\theta_{j}-n\right)^{2}\right]=\left(\alpha^{W}-\theta_{j}\right)$

as the spouses' fertility private optima in this case.

\footnotetext{
${ }^{13}$ One remark is worth making: since the wife's outside option assures her to minimize her expected utility cost, the husband will always make an offer to make her indifferent between her optimal fertility and transfers. The distance between the wife's optimal fertility and that proposed by the husband is pinned down by $\gamma$. Indeed, in a Pareto optimal problem in which the husband maximizes his utility under the constraint that the utility of the wife be higher or equal to 0, the Lagrange multiplier on the wife's utility constraint is equal to $\gamma$. In this sense, this parameter can also be interpreted as a proxy for the bargaining power of the woman in the couple.

${ }^{14}$ The assumption also allows to express our theoretical predictions with respect to $\alpha^{H}$, matching our baseline evidence on the role of husband's preferences and hence our stratification variables for heterogeneity. However, all the theoretical results related to communication and transfers are symmetric around $\alpha^{H}-\alpha^{W}=0$.
} 


\subsubsection{Structure of household decision making}

The structure of the decision-making is as follows: given the wife's preferences and beliefs, the husband computes the optimal mapping from transfers to fertility $n(t)$ so that the utility of the wife remains unchanged, and he chooses the optimal level of transfers $t^{*}$, making a take-itor-leave-it offer to the wife. Then, optimal fertility $n^{*}$ is realized. We have in mind an efficient contracting environment where the husband can compensate the wife for her utility loss. The model is solved by backward induction.

\subsubsection{Equilibrium transfers and number of children}

First, the husband computes the optimal transfers that would induce a fertility shift in favor of his own preferences. He knows that the wife will implement her optimum $n_{j}^{W}$ unless she receives a transfer that compensates her for deviating. We characterize the wife's fertility choice as a function of transfers in the following way:

$$
n(t)=\left\{\begin{array}{llc}
n_{j}^{W} & \text { if } & t=0 \\
n_{j}^{H t} & \text { if } & t \geq\left(\alpha^{W}-\theta_{j}-n_{j}^{H t}\right)^{2}
\end{array}\right.
$$

where $n_{j}^{H t}$ is the optimal number of children for the husband when transfers occur. Maximizing the husband's utility function with transfers accounting for the wife's reaction, we have: $n_{j}^{H t}=\frac{n_{j}^{H}+\gamma n_{j}^{W}}{1+\gamma}$. At the optimum, the husband chooses $t^{*}=\left(n_{j}^{H t}-n_{j}^{W}\right)^{2}>0$.

In equilibrium, transfers always occur and the optimal number of children in equilibrium is the optimum for the husband in the presence of such transfers $n_{j}^{*}=n_{j}^{H t}$.

\subsection{Fertility with incomplete information}

We now study equilibrium fertility for the two types of households that we consider, the equally uninformed households and the asymmetrically uninformed households. In the latter case, in which the wife has perfect knowledge of the cost realization and the husband does not, we study the communication game about the cost realization.

\subsubsection{Equally uninformed household}

Consider the case in which both spouses do not perfectly observe the realization of the health cost and they have a biased perception of the distribution of the health cost with mean $\theta^{G}$. The 
structure of the game is the same as before.

The structure of the game is the same as before. The game is solved by backward induction.

Privately optimal fertility The private optimal fertility of the two spouses, that maximize their expected utility, given the new assumption on the distribution of the maternal health cost is now equal to:

$$
n_{b}^{W}=\alpha^{W}-\theta^{G} ; \quad n_{b}^{H}=\alpha^{H}-\delta \theta^{G} .
$$

Equilibrium transfers and number of children This time, maximising the husband utility function with transfers, we have: $n_{b}^{H t}=\frac{n_{b}^{H}+\gamma n_{b}^{W}}{1+\gamma}$. Even with biased beliefs, the husband's incentive compatibility condition is always satisfied, so the optimal fertility in equilibrium is equal to $n_{b}^{*}=n_{b}^{H t}$.

\subsubsection{Asymmetrically informed household}

We now consider the case in which the wife is perfectly informed about the cost realization $\theta_{j}$ and the husband is not. The structure of the game is modified as now there is the possibility of a communication stage in which the wife can try to provide information about her health cost realization. The structure of the game is modified as follows:

1. The wife communicates about $\theta_{j}$

2. The husband updates $\theta_{j}$ and offers $t\left(n_{u}^{*}\right)$ with commitment

3. The wife accept or refuses $n_{u}^{*}$

4. The husband pays $t\left(n_{u}^{*}\right)$

Again, the model is solved by backward induction.

Optimal Fertility and Transfers Given that the wife is informed, her privately optimal fertility is equal to the complete information case: $n_{j}^{W}=\alpha^{W}-\theta_{j}$, while that of the husband depends on his beliefs about $\theta_{j}$, and is equal to $n_{u}^{H}=\alpha^{H}-\delta E_{H}\left[\theta_{j}\right]$, where $E_{H}\left[\theta_{j}\right]$ is the husband's posterior on the expected maternal health cost of the wife after communication takes place. 
Maximizing the husband's utility function with transfers, we have that equilibrium fertility with transfers is equal to $n_{u}^{H t}=\frac{n_{u}^{H}+\gamma\left(\alpha^{W}-E_{H}\left[\theta_{j}\right]\right)}{1+\gamma}$.

To understand when it is optimal for the husband to give a transfer to his wife, we need to study the communication game in the first stage.

Communication Studying information sharing by the wife and information updating by the husband, we have the following lemma.

Lemma 1. When the wife perfectly observes the realization of $\theta_{j}$, no informative communication occurs between her and her husband, unless preferences are aligned $\left(\alpha^{H}-\alpha^{W}=0\right.$ and $\left.\delta>\frac{1-\gamma}{2}\right)$. Under Assumption 1, transfers and fertility behave as follows:

(i) For a given $\alpha^{W}$, when $\alpha^{H}$ is high enough, transfers occur and fertility is based on the husband's optimal choice;

(i) otherwise, fertility follows the woman's optimum $n_{j}^{*}=\alpha^{W}-\theta_{j}$.

Proof. See Appendix B

The lack of information transmission is linked to the control the wife has on fertility: when transfers do not occur, the wife implements her private optimum, that implies no utility loss. When she has to transmit information, her incentives are such that she tries to push transfers beyond her utility loss, to reach an indirect utility higher than her back-up option. Since these incentives are independent from the cost realisation, no information can be transmitted and a pooling equilibrium is the only equilibrium possible.

\subsection{Fertility and communication after the intervention}

We now discuss the effect of an informational intervention that credibly communicates $\theta_{j}$ to participants, such as the one in our study.

\subsubsection{Wife treated with information}

When the wife is treated, she gets a perfectly informative signal on her cost realization. When the wife is already informed prior to the intervention, no change occurs. When she and her husband are uninformed, however, the households may be affected by the information. 
Studying the aggregate change in communication and fertility after the intervention when the wife is treated, we have the following result:

Proposition 1. After the intervention, when the wife is treated, no informative communication occurs between her and her husband, unless preferences are aligned $\left(\alpha^{H}-\alpha^{W}=0\right.$ and $\left.\delta>\frac{1-\gamma}{2}\right)$. Under Assumption 1, when $\alpha^{H}$ is low, transfers and fertility decrease in households in which the wife was ex ante uninformed. When $\alpha^{H}$ is high, transfers slightly increase and fertility slightly decreases in households in which the wife was ex ante uninformed.

Proof. See Appendix B

\subsubsection{Husband treated with information}

In the husband treatment arm, the husband receives a perfectly informative signal. Because all men are ex ante uninformed, all types of households are affected. The households in which the wife was informed and the husband was not (the asymmetrically informed households) become households in which everybody is fully informed. For the other type of households, the equally uninformed ones, we now have asymmetry of information (but reversed by gender), and we have to study the information transmission from the husband to the wife.

Optimal actions when the husband is informed We now analyze the case in which the husband is perfectly informed about the cost realization and the wife is not. This corresponds to our intervention treatment, in which we provide precise information on maternal health to the husband, whenever the wife is not already perfectly informed herself.

The main difference with the case in which the wife has to communicate comes from the fact that the husband transmits information through the transfer he offers to the wife, and that he can get to his private optimum by offering the appropriate transfer. In other words, transfers can provide a signal of the health cost realization to the wife.

Structure of household decision making Again, the structure of the game is modified to account for the possibility of communication between husband and wife. The husband can provide information about the health cost realization $\theta_{j}$ to the wife. The structure of the game is as follows:

1. The husband offers $t\left(n\left(\theta_{j}\right), E_{W}\left[\theta_{j}\right]\right)$ signaling $\theta_{j}$ 
2. The wife updates about $\theta_{j}$ and accept or refuses $t\left(n\left(\theta_{j}\right), E_{W}\left[\theta_{j}\right]\right)$

3. The husband pays $t\left(n^{*}\right)$

where $E_{W}\left[\theta_{j}\right]$ is the information the wife has after Bayesian updating occurs, based on the message of the husband.

The Bayesian Nash equilibrium of the game is such that the equilibrium fertility is determined by the offer of the husband, that also signals $\theta_{j}$, and transfers are based on the posterior of the wife about $\theta_{j}$.

Equilibrium transfers and number of children The equilibrium fertility that the husband asks when proposing the transfers to the wife is $n_{v}^{H t}=\frac{n_{h}\left(m\left(\theta_{j}\right)\right)+\gamma\left(\alpha^{W}-m\left(\theta_{j}\right)\right)}{1+\gamma}$. This constitutes an informative signal of the cost realisation since the husband commits to pay transfers based on this fertility level.

Transfers are aligned to the wife's information set. When the wife has a posterior equal to $E_{W}\left[\theta_{j}\right]$, transfers are determined based on the fertility outcome and the wife receives $t=$ $\left(\alpha^{W}-E_{W}\left[\theta_{j}\right]-n_{v}^{H t}\right)^{2}$, so that her level of indirect utility is equal to 0 , her outside option. ${ }^{15}$

Communication To study information sharing by the husband and information updating by the wife, we have to understand the husband's incentives to truthfully report the maternal health $\operatorname{cost} \theta_{j}$.

When $\delta$ is sufficiently high and $\gamma$ is sufficiently low, the husband always gets the highest level of utility telling the truth, so truthful communication occurs in equilibrium. When $\gamma$ is very high, the husband has no incentives to tell the truth, and no communication occurs in equilibrium. This is due to the fact that the wife is aware that any information sharing by the husband would aim at minimizing transfers, regardless of the realization of $\theta$. For intermediate levels of $\delta$ and $\gamma$, there is some information updating, without full information transmission. The information updating depends on the difference in ideal fertility between the husband and the wife (see the proof of proposition 2 for the details).

As soon as some information transmission occurs, average fertility is affected as well. Communication, transfers and fertility are affected in the following way:

\footnotetext{
${ }^{15}$ The husband always prefers to make a transfer since, without a transfer, fertility would coincide with the wife's ideal fertility in expectation $n^{W}=\alpha^{W}-E_{W}\left[\theta_{j}\right]$.
} 
Proposition 2. After the intervention, when the husband is treated and both spouses were ex ante uninformed, for $\delta$ sufficiently high and $\alpha^{H}$ sufficiently small, or for $\gamma$ sufficiently low, informative communication about $\theta_{j}$ occurs. Transfers increase in all households with sufficiently low $\alpha^{H}$. Fertility decreases among:

(i) households in which the wife was informed and $\alpha^{H}$ is high, provided $\gamma$ is sufficiently low;

(ii) households in which the wife was previously uninformed and $\alpha^{H}$ is low.

(iii) households in which the wife was previously uninformed and $\gamma$ is low.

Proof. See Appendix B

The results on information transmission between husband and wife rely on the specificity of the fertility agreement: the husband can implement his optimal fertility through transfers. When the difference in ideal fertility or the cost of transfers are sufficiently low, optimal transfers differ across cost types and this implies a unique separating equilibrium. For higher levels of difference in ideal fertility or transfers cost, partial or no information transmission occur. Standard refinements of equilibria apply. ${ }^{16}$

\subsection{Experimental predictions}

In the previous subsections, we formally described how communication, transfers and fertility are affected by the intervention: while average fertility is expected to decrease both when we treat the husband and the wife, communication and transfers evolve very differently across the two treatments, leading to different implications for policy purposes.

We can hence formulate several predictions for how our outcomes of interest would be affected by the intervention, that we can formally test using our experimental data from Zambia. The proofs of the predictions are in the Appendix. The first two predictions relate to primary outcomes: maternal health knowledge and fertility.

Prediction 1. Communication and beliefs updating. After the intervention,

(i) when the wife is treated, no information transmission occurs between husband and wife and beliefs evolve on average only for the wife;

\footnotetext{
${ }^{16}$ NITS condition applies for values of parameters not satisfying the monotonicity of the message function defined by the differential equation 5 (Chen, Kartik and Sobel, 2007). When a separating equilibrium exists, the intuitive criterion apply (Cho and Kreps, 1987). See the proof in appendix for details.
} 
(ii) when the husband is treated, information transmission occurs when interests are sufficiently aligned (for $\delta$ sufficiently high and $\alpha^{H}$ sufficiently small, or for $\gamma$ sufficiently low), and beliefs evolve on average for both spouses.

Prediction 2. Fertility. After the intervention, fertility decreases both when men are treated and when women are treated.

Fertility is expected to move both when the husbands and the wives are treated. Since beliefs moves more often when the husband is treated, the average effect may be higher than when the wife is treated.

The third prediction is about a secondary outcome, affected indirectly by the intervention: the transfers between husband and wife.

Prediction 3. Transfers. After the intervention,

(i) when the wife is treated, transfers to the wife decrease on average;

(ii) when the husband is treated, transfers to the wife increase on average.

Finally, we present some predictions about heterogeneous effects of the intervention along two dimensions: the fertility preferences of the husband and the idiosyncratic health cost faced by the wife.

Prediction 4. Ex ante fertility preferences After the intervention, heterogeneous effects according to the husband's ex ante fertility preferences are as follows:

(i) communication occurs when the husband is treated and $\alpha^{H}$ is low;

(ii) fertility decreases both when the wife is treated and when the husband is treated. When the wife is treated, the effect is concentrated in households in which $\alpha^{H}$ is low. When the husband is treated, fertility decreases for any value of $\alpha^{H}$, with a strongest effect when $\alpha^{H}$ is low.

The heterogeneous effects with respect to transfers mirrors the effects for fertility when $\alpha^{H}$ is high: they increase only when the husband is treated. When $\alpha^{H}$ is low, transfers decrease when the wife is treated. When the husband is treated the effect is ambiguous, as transfers are expected to increase when the husband wants more children then the wife, and decrease when he wants less children then her as long as $\delta$ is lower than 1 . 
Prediction 5. Ex ante health cost of the wife After the intervention, heterogeneous effects according to the ex ante health cost of the wife are as follows:

(i) when $\theta_{j}$ is low, fertility does not change neither when the husband is treated nor when the wife is treated;

(ii) when $\theta_{j}$ is high, fertility decreases both when the husband is treated and when the wife is treated.

All the proofs are in Appendix B. Prediction 1 is tested in section 5.1. Prediction 2 is tested in section 5.2. Prediction 3 is tested in section 5.3. Finally, the heterogeneous effects described in prediction 4 and 5 above are tested in section 5.4 .

\section{The experiment}

To study and compare the effect of providing information about maternal mortality to men and women, we designed and implemented a randomized field experiment among couples in Lusaka, Zambia.

\subsection{Design}

Our intervention experimentally varied the provision of information about maternal health risk to either the husband or the wife of each household relative to a control group. Both spouses in all households were invited to participate in a gender-specific group meeting. In order to identify gender differences in responsiveness to information separately from potential gender differences in take-up, only households in which both husbands and wives agreed to participate were included in the study. Each household was randomly assigned to one of three study arms (see table 2):

i) The husband was exposed to both a maternal mortality curriculum and a family planning curriculum $(F P+M M)^{h}$ and the wife was exposed to the family planning curriculum $F P^{w}$. This arm is denoted in short as $F P+M M^{h}$.

ii) The wife was exposed to both the maternal mortality curriculum and the family planning curriculum $(F P+M M)^{w}$ and the husband was exposed to the family planning $F P^{h}$ curriculum. This arm is denoted in short as $F P+M M^{w}$.

iii) Both spouses received the FP curriculum. This arm is hence denoted in short as FP. 
Table 2: Experimental design

\begin{tabular}{|ll|c|c|}
\hline & & Husband & Wife \\
\hline Husband treated & {$\left[F P+M M^{h}\right]$} & $(F P+M M)$ & $F P$ \\
\hline Wife treated & {$\left[F P+M M^{w}\right]$} & $F P$ & $(F P+M M)$ \\
\hline Control & {$[F P]$} & $F P$ & $F P$ \\
\hline
\end{tabular}

\subsection{Identification and empirical specification}

The primary rationale for our design is to identify the direct and indirect effects of providing information on maternal mortality to men and women. The fact that information is always delivered in a group setting and alongside information about family planning ensures that all participants are exposed to both the group meeting setting and the family planning information. Although the control group may be influenced by the family planning information itself, making some effects potentially harder to detect, this design feature unambiguously isolates the incremental effects of the maternal mortality information.

Our experiment focuses on two sets of empirical objects. First, we are interested in separately estimating the average treatment effects of delivering both maternal health and family planning information $\left((F P+M M)^{j}\right)$ to each spouse $j \in\{h, w\}$ compared to delivering family planning information alone $\left((F P)^{j}\right)$ on a hypothetical outcome of interest $Y$, measured at either the household level(e.g. take up of family planning and fertility) or the individual level (e.g. knowledge of maternal health, attitudes towards family planning), for either the treated spouse (direct effect) or the untreated spouse (indirect or spillover effect). In order to estimate this object, we would ideally estimate $A T E^{j}=E\left[Y(F P+M M)^{j}\right]-E\left[Y(F P)^{j}\right]$. The second object we are interested in estimating is the comparison of the (direct or spillover) impact of providing information about maternal mortality to men compared to women on household-level and individual-level outcomes; that is, for example, $\triangle A T E=A T E^{h}-A T E^{w}$.

The main challenge associated with estimating these objects is that, in our design, participants choose to attend a community meeting, generating an imperfect take-up problem. This challenge is addressed by our standard double-blind approach: the surveyors who invite households to the community meetings do not know what type of meeting each individual is invited to and only one type of invitation card is provided to participants in all treatment arms, ensuring that selection into participation in the community workshop is the same within genders, and 
hence that we can estimate a treatment-on-the-treated effect $T O T^{j}$ within husbands and wives separately.

Even with double-blind invitations, we may be left with a second concern: that the pool of women and men who decide to attend the community meeting may come from different types of households, if the characteristics that govern the selection into participation of treated men differ from those governing the selection of treated women. ${ }^{17}$ If this is the case, then the difference in the treatment-on-the-treated effects by gender may not only be driven by the differential impact of maternal health information on men compared to women, but also by the differential take-up:

$$
\left[E\left[Y(F P+M M)^{h}-Y(F P)^{h} \mid p^{h}=1\right]\right]-\left[E\left[Y(F P+M M)^{w}-Y(F P)^{w} \mid p^{w}=1\right]\right]
$$

where $p^{j}$ takes value 1 when spouse $j$ attends the community meeting and 0 otherwise (takeup).

To address this issue, we chose to invite both spouses to attend workshops together, and hence to have a three-arm design in which men and women in all households receive information on family planning, while the treated spouse receives maternal health information as well. Considering households in which both spouses have attended a community workshop implies estimating $\triangle T O T$, which identifies the difference in the treatment-on-the-treated effects estimated on directly comparable samples:

$$
\begin{aligned}
\Delta T O T & =E\left[\left(Y\left(F P+M M^{h}\right)-Y(F P)\right) \mid p^{h}=1, p^{w}=1\right] \\
& -E\left[\left(Y\left(F P+M M^{w}\right)-Y(F P)\right) \mid p^{h}=1, p^{w}=1\right] \\
& =E\left[\left(Y\left(F P+M M^{h}\right)-Y\left(F P+M M^{w}\right)\right) \mid p^{h}=1, p^{w}=1\right] .
\end{aligned}
$$

The cost of achieving this comparability is that we can only estimate the effect of receiving a maternal mortality intervention when both spouses are exposed to the family planning curriculum. This setup can then allows us to study both the direct effects of the intervention on treated respondents and the indirect effects on the respondents' spouse.

Our estimation equations follow straightforwardly from our design. When considering out-

\footnotetext{
${ }^{17}$ Suppose, for example, that women from more conservative households are unable to attend a meeting on their own, while their husbands would be willing to participate. If conservative households have different treatment effects from the rest of the sample, we may detect a difference between treatment effects across arms that depends on take-up and not on differential effects across genders.
} 
come $Y$ for household $i$ (e.g. fertility), we estimate the following specification on the sample of treated households:

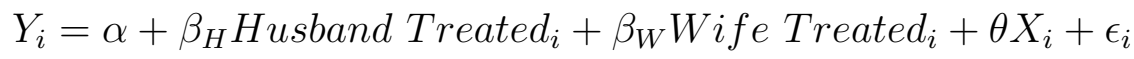

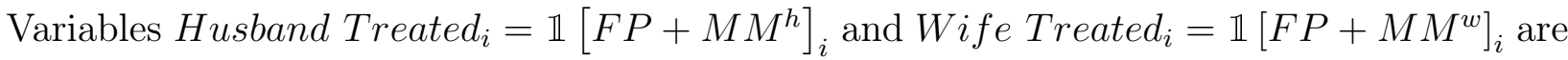
indicators for assignment to either the husband's or the wife's treatment arm. Hence, $\beta_{H}$ and $\beta_{W}$ identify the average treatment-on-the-treated effects for men and women respectively, while their difference captures the difference in the effect of treating a given spouse (equation 1). In the tables, we report the p-value of this F-test. The vector of baseline control variables $X_{i}$ includes wife's age, husband's age, wife's education, husband's education, number of children, age of last child born before the group meeting, number of people who attended the group meeting, modern contraceptive use at baseline, quadratic weekly income plus the stratification variables. ${ }^{18}$ As a robustness check, in the Appendix, we also perform post double selection LASSO to select the control variables.

We also consider specifications in which the outcome variable is measured at the individual, rather than household, level for spouse $j \in\{h, w\}$ in household $i$ (e.g. beliefs). Our design allows us to compare the direct effect of treating a subject with the spillover (indirect treatment) effect on his or her partner, by estimating

$$
\begin{aligned}
& Y_{i}^{j}=\delta_{H}^{h} \text { Husband Respondent }_{j} \times{\text { Husband } \text { Treated }_{i}+\delta_{W}^{h} \text { Husband Respondent }_{j} \times \text { Wife }_{\text {Treated }}}_{i} \\
& +\delta_{H}^{w} \text { Wife Respondent }_{j} \times{\text { Husband } \text { Treated }_{i}+\delta_{W}^{w} \text { Wife Respondent }_{j} \times \text { Wife }_{\text {Treated }}} \\
& +\zeta X_{i}+\eta X_{i} \times \text { Husband Respondent }{ }_{j}+v_{i, j}
\end{aligned}
$$

where Husband Respondent R $_{j}=\mathbb{1}[j=h]$ and Wife Respondent R $_{j}=\mathbb{1}[j=w]$ are dummies capturing the identity of the respondent. Here, the coefficients have the following interpretation: i) $\delta_{H}^{h}$ represents the direct effect of treating the husband on the husband's outcome variable $Y_{i}^{h}$; ii) $\delta_{W}^{h}$ represent the spillover effect of treating the wife on the husband's outcome $Y_{i}^{h}$;

\footnotetext{
${ }^{18}$ Stratification variables are primarily variables likely to affect the relevance of maternal health information for fertility decisions: i) a dummy for whether wife over 35; ii) a dummy for whether the couple is childless; iii) a dummy for whether the wife thinks that the husband wants another child later and for whether the wife thinks the husband does not want another child; iv) a dummy for whether the husband does not know any woman who died at childbirth; v) a dummy for whether the wife is actively trying to get pregnant; vi) block size; vii) availability of baseline data.
} 
iii) $\delta_{H}^{w}$ represents the spillover effect of treating the husband on the wife's outcome variable $Y_{i}^{w}$ iv) $\delta_{W}^{w}$ represent the direct effect of treating the wife on the wife's outcome $Y_{i}^{w}$.

We report the p-values of the following F-tests:

i) the difference between direct and spillover effects on the husband, i.e. between the effect of treating the husband himself or his wife on the husband's answer $\left(\delta_{H}^{h}=\delta_{W}^{h}\right)$, denoted as Direct vs. spillover effect on husband F-test p-value;

ii) the difference between direct and spillover effects on the wife, i.e. between the effect of treating the wife herself or her husband on the wife's answer $\left(\delta_{W}^{w}=\delta_{H}^{w}\right)$, denoted as Direct vs. spillover effect on wife F-test p-value;

iii) the difference between spillover effects, i.e. between the effect of treating the husband on the wife's answer and that of treating the wife on the husband's answer $\left(\delta_{H}^{w}=\delta_{W}^{h}\right)$, denoted as Symmetry of intra-household spillover effects F-test p-value;

iv) the difference between direct effects, i.e. between the effect of treating the husband on his answer and that of treating the wife on her answer $\left(\delta_{H}^{h}=\delta_{W}^{w}\right)$, denoted as Direct treatment effects F-test p-value.

\section{Implementation and data collection}

The study involved two waves of a panel household survey, administered separately to both the husband and the wife of each household, and a randomized controlled trial.

\subsection{Sample}

Couples were recruited from the catchment area of Chipata and Chaisa Clinics, located in the poor suburbs of Lusaka. The sample is representative of the peri-urban population of Zambia. Eligibility for the study followed exclusion criteria meant either to protect women that may face adverse consequences if using hormonal contraception or to exclude women that could not adjust their fertility behavior to the information provided in the intervention. ${ }^{19}$

\footnotetext{
${ }^{19}$ Any couple in which the wife was aged between 18 and 40 and lived in the catchment area of the Chipata and Chaisa clinic was eligible to be recruited. A random-address generator was used to recruit couples. The following exclusion criteria was agreed upon with the competent Research Ethics Committees: (i) households in which the wife had diabetes, heart disease or high blood pressure at baseline; (ii) households in which the wife was younger than 18 years of age or older than 40 at baseline; (iii) households in which the wife was less than 8 weeks postpartum; (iv) households in which the wife has been sterilized or had a hysterectomy; (v) men or women who were not currently married; (vi) households in which the wife was pregnant at recruitment or
} 


\subsection{Data collection and intervention}

The first wave of data consisted of a baseline survey in the first visit administered both to the husband and the wife. Baseline data collection occurred between August and December 2014. 715 couples were interviewed, with the husband and the wife surveyed separately. The sample was re-screened prior to the actual start of the intervention, which occurred in November 2015. In order to determine which treatment arm each household was assigned to, we randomized treatment at the couple level stratifying on the following characteristics: (i) whether the couple had a child or not; (ii) whether the wife was older or younger than 35 years old; (iii) whether the couple wanted another child at baseline; (iv) residential size of the block in which the couple lived; (v) whether the wife believed that the husband wanted another child; (vi) whether the wife believed that the husband wanted another child as soon as possible; (vii) whether the husband knew someone who died at childbirth.

The intervention stage took place between November 2015 and May 2016. It involved a community meeting - in which spouses would receive information on maternal health related issues and family planning - occurring during weekends. Households were invited to attend on a weekly roll-out basis. We randomly varied the first intervention week by treatment arm for each household. To avoid contamination across treatment arms, each type of community meeting took place in a different time slot. This implied that there was a non-negligible amount of time between the randomization and the actual invitation to the intervention.

The lag between the baseline data collection and the intervention led to a strong reduction in eligibility in the sample. Hence, between October 2015 and February 2016, 442 households were subsequently included in the sample. For these households, a subset of baseline questions was asked to the wife for stratification purposes. ${ }^{20}$ Thus, the sample of households eligible for intervention consists of 1,137 couples. Of these, in total, 772 households were eligible to be invited to the intervention. This implies that $21 \%$ of the sample became ineligible between baseline and intervention, mostly due to pregnancy and to shifts outside the catchment area

the intervention phase; (vii) households in which the spouses were actively trying to have a baby when invited for the intervention; (viii) households in which the wife was on long-term contraceptives when invited for the intervention. Exclusion criteria (iv) to (vii) relate to our study objectives, but are not medically motivated.

${ }^{20}$ These additional couples were enrolled in the study if they satisfied the eligibility criteria and consented to participate. While other study participants took part in a baseline survey before being invited to community meetings, these couples did not undergo a complete baseline, but the wife answered a small subset if the baseline questions, crucial for our heterogeneity analysis. We first recruited these households, then went back and conducted the invitations to community meetings, similar to the rest of the sample. 
of our partner clinics. Recruitment and invitations were double-blind and drop-outs occurred before treatment assignment, and hence it is orthogonal to it.

Participants were asked to show up for the meetings together with their spouse, and were separated into different rooms for parallel, gender-specific sessions. Participants were not told the content of their partner's session. Each session involved approximately 20 participants and was led by two trained local facilitators, one man and one woman, each working in meetings of men and women to ensure we do not include a facilitator-specific effect in the treatment effect. In the FP curriculum, the educators discussed the types of modern contraceptives available at the clinic, dispelled common misconceptions surrounding family planning, and referred the participants to the public clinic for further information. In the $\mathrm{FP}+\mathrm{MM}$ curriculum, the educators delivered this same information, but also added informational content about maternal health risk. The material focused on the magnitude of the risk of maternal mortality in Zambia, the primary medical causes of maternal mortality and morbidity and the risk factors such as low birth spacing, high parity and advanced age.

The trained facilitators followed a scripted curriculum, helped by visual material designed for the study. These features allowed our team to extensively monitor the information presented and ensure consistency across groups. All scripts are included in Appendix C. Illustrated materials, designed by a local artist for the study and organized in flipcharts, supported the group meeting.

We tested and implemented a number of steps to maximize participants' attendance to the community workshops. First, workshops were held on weekends. The exact time of the workshops was decided based on focus group discussions and a small survey. Assignment of workshop time slots to study arms was randomized. Second, couples who missed their first community workshops were re-invited again several additional times. Third, each spouse received 25 Zambian Kwacha (approximately 5 USD at the time of the intervention) as transport reimbursement, an amount comparable to the amounts households receive in Lusaka for attending this type of events. Last, a raffle was associated with each set of workshops, and only participants to the workshop received a raffle ticket for winning a small electric cooking stove. In the end, a total of 562 couples attended out of 772 (73\% of invited couples) attended a group meeting.

After the group meetings, we used a Becker-DeGroot-Marschak mechanism to elicit the participants' willingness to pay (WTP). We elicited the husband's WTP for a voucher to get priority access to family planning services at the public clinic, to test whether the maternal 
health curriculum had any immediate effect on the demand for contraceptives. The facilitators explained to the participants that the voucher granted access to a nurse dedicated to the study, who would provide them with information about family planning and with any method of their choice, similar to the voucher that was provided in the (Ashraf, Field and Lee, 2014) study.

Finally, between October 2016 and March 2017, we collected follow-up data for the households that attended the intervention, with an attrition rate of 10\%: for those households, we recollected measures of knowledge of maternal health, use of and attitudes toward contraception, balance of power, fertility demand and realized fertility. Attrition is comparable across treatment arms.

\section{Empirical findings}

In this section, we report the empirical findings from the experiment. We begin by examining changes in knowledge and beliefs about maternal mortality, and the flow of such information within the household. We then study how providing maternal health information affects fertility, transfers and relationship well-being. Finally, we examine the model's empirical predictions with respect to heterogeneous treatment effects.

\subsection{Knowledge and beliefs about maternal health}

We begin by examining the effect of treatment on knowledge and beliefs about maternal health risk. First, to measure what participants have retained from the session, we consider an index that combined the two main sets of questions on beliefs. The first set of questions asks respondents to identify risk factors for maternal complications, such as advanced maternal age, high parity and low birth spacing, all discussed during the treatment workshops. The second set of questions are ladder scale questions in which respondents are asked to report, on a scale from 0 to 10, the likelihood that a woman with fixed characteristics would experience birth complications. We build an index averaging the six (standardized) questions about risk factors and the seven (standardized) ladder scale questions, and also look at the risk factor and ladder questions as separate indices.

Relative to the control group, we observe a significant increase in maternal health risk awareness among treated men and also among treated women, a noisy increase among the wives of 
treated men, and a decline among the husbands of treated women (table 3, column 1). Our Wald tests indicate that direct effects of treatment differ significantly from the indirect effects on men (p-value less than 0.001) but not on women, and therefore that spillovers within the household are asymmetric (p-value 0.022).

When we examine the risk factors questions alone in a single index, we detect even clearer patterns with respect to our theoretical predictions. In particular, we observe a very stark and statistically significant increase in awareness of risk factors in the answers given by both treated husbands and treated wives (table 3, column 2). Even more interestingly, we find clearer evidence of a spillover effect of the treatment from husbands to wives: the wives of treated husbands also exhibit an increase in awareness of maternal health risk factors. Meanwhile, in line with the predictions of our model, we find no spillover effects flowing from treated wives to their husband. We can firmly rule out that treating the wife and treating the husband have the same impacts on men's knowledge of risk factors (p-value less than 0.001), while no such difference is detected in women's updating. As a result, we can rule out that spillover effects are symmetric within the household ( $\mathrm{p}$-value equal to 0.097). Women learn from their husbands about maternal risk factors, but men do not appear to learn from their wives when the wives update their own beliefs. In Appendix table A5, we report the effect of treatment on each of the components of the risk factors index.

Finally, answers to the ladder scale questions bear qualitatively similar results, but are substantially more noisy, as we can see by examining an index. We do not find a statistically significant increase of the index variable that combined all standardized ladder scale questions in response to treatment in any subgroup (table 3, column 3). Male respondents married to treated wives actually appear to report a lower perceived likelihood of complications. Overall, treating the wife has a statistically significantly different effect than treating the husband on the husband's ladder scale responses ( $p$-value of the direct vs spillover effect on husband is less than 0.030), while no such difference is detected in the wife's answers. Again, we can rule out that spillover effects are symmetric (p-value equal to 0.060). When we examine the components of this ladder scale index, we find the same pattern as for the risk factors on the question that involves a high-risk group: women aged 40 and above (Appendix table A6 column 2). Relative to the control group, treated husbands, treated wives, and wives of treated husbands all report a higher perceived likelihood for this hypothetical group, while no effect can be detected for 
Table 3: Knowledge and Beliefs Indices

\begin{tabular}{lcccc}
\hline \hline & $\begin{array}{c}(1) \\
\text { Beliefs }\end{array}$ & $\begin{array}{c}(2) \\
\text { Risk factors } \\
\text { Index }\end{array}$ & $\begin{array}{c}\text { Ladder } \\
\text { Index }\end{array}$ \\
\hline H Respondent $\times$ H Treated $\left(\delta_{H}^{h}\right)$ & $\begin{array}{c}\text { Index } \\
\text { H Respondent } \times \text { W Treated }\left(\delta_{W}^{h}\right)\end{array}$ & 0.074 & 0.143 & 0.014 \\
& {$[0.038)$} & $(0.053)$ & $(0.052)$ \\
& {$[0.055]$} & {$[0.008]$} & {$[0.783]$} \\
H Respondent $\times$ H Treated $\left(\delta_{H}^{w}\right)$ & -0.072 & -0.039 & -0.101 \\
& $(0.037)$ & $(0.052)$ & $(0.053)$ \\
& {$[0.057]$} & {$[0.459]$} & {$[0.059]$} \\
W Respondent $\times$ W Treated $\left(\delta_{W}^{w}\right)$ & 0.054 & 0.083 & 0.030 \\
& $(0.039)$ & $(0.050)$ & $(0.047)$ \\
Stratification Variables & {$[0.169]$} & {$[0.100]$} & {$[0.527]$} \\
Demographic Controls & 0.094 & 0.100 & 0.083 \\
H Respondent Interactions & $(0.043)$ & $(0.052)$ & $(0.054)$ \\
F-test p-values: & {$[0.034]$} & {$[0.057]$} & {$[0.124]$} \\
Direct vs. spillover effect on husband $\left(\delta_{H}^{h}=\delta_{W}^{h}\right)$ & Yes & Yes & Yes \\
Direct vs. spillover effect on wife $\left(\delta_{W}^{w}=\delta_{H}^{w}\right)$ & Yes & Yes & Yes \\
Symmetry of intra-hh spillover effects $\left(\delta_{H}^{w}=\delta_{W}^{h}\right)$ & 0.000 & 0.000 & 0.030 \\
Direct treatment effects $\left(\delta_{H}^{h}=\delta_{W}^{w}\right)$ & 0.022 & 0.097 & 0.060 \\
Observations & 0.729 & 0.561 & 0.350 \\
\hline \hline & 1050 & 1050 & 1050 \\
\hline
\end{tabular}

Notes: SE clustered at the meeting level in parentheses. P-values in brackets. Index variable in column 1 is the mean of all standardized variables in Appendix tables A5 (risk factors) and A6 (likelihood scales), with the index for each of the tables appearing in column 2 and 3 respectively. Stratifying control variables include if couple has children, wife over 35, wife thinks that husband wants another child later, wife thinks husband does not want another child, husband does not know of women who died at childbirth, block size, and baseline data present. Demographic control variables include wife age, husband age, wife education, husband education, number of children, age of last child born before meeting, wife is actively trying to get pregnant, baseline contraceptive use, and household weekly income. Each control variable and the constant are also interacted with a dummy for the husband being the respondent.

husbands of treated wife. ${ }^{21}$ Moreover, we note that the negative effect of treating the wife on the husband's responses that we detect in the index appears to be driven by the beliefs over the relatively low-risk groups, and especially women with fewer than four children (column 3) and women who become pregnant after adequate spacing (column 5).

Considering the three indices together, the data indicate a strong pattern of greater maternal health risk awareness among men and women as a result of the intervention, except among men

\footnotetext{
${ }^{21}$ In Appendix figure A3, we plot the shift in the distribution of this likelihood scale question. We observe a clear positive shift in all respondent groups' answers, except the husbands of treated women.
} 
whose wives are given the information. In fact, we observe some evidence that men actually update negatively when their wives are treated, though this is not observed in the risk factors index. That pattern could potentially reflect a backlash towards a wife initiating communication with her husband post-treatment, which is perceived by him as an exaggeration. This reminder could potentially lead him to update even further away from his low-risk prior, but would not lead him to mischaracterize the risk factors of maternal mortality, consistent with the lack of a significant negative effect in column 2 .

Our model hypothesizes that treating husbands would raise intra-household communication about maternal health, which could explain how untreated women married to treated men report different beliefs compared to the control group. We also examine this hypothesis directly by considering an array of questions about intra-household communications over reproductive health. We find that treated men report more communication with their spouse over maternal mortality and contraceptive use (Appendix table A7, column 1 for the index variable). In particular, treated men are the only subgroup that reports increased communication over maternal mortality relative to the control group (columns 2 and 3). Husbands of treated women do not report increased communication over maternal health; they do however report a statistically significant increase in the probability that their wife has tried to convince them to use contraceptives (columns 6), which could potentially account for the backlash observed in the previous table. That is, when treated women try to convince their husbands of the importance of family planning due to their updated beliefs about maternal risk, their husbands (who were at the same time exposed to the family planning information provided to every participant, including in the control group) perceive it to be an attempt at persuading them to have fewer children. They may thus "overcorrect" their beliefs on health risk.

\subsection{Pregnancy and fertility}

We next examine how updating beliefs on maternal risk translates into realized fertility outcomes. Our primary outcome of interest is pregnancy, and we consider that alongside expected future fertility. In particular, we measure whether the wife reports being pregnant at endline (table 4 column 2), whether she became pregnant or gave birth starting 8 months after the intervention (column 3), her reported likelihood of having more children on a 0-10 ladder scale 
(column 4), and the spacing between the intervention and birth (column 5). ${ }^{22}$ An index of these variables, computed as the average of their standardized transformation, is reported in column 1.

Table 4: Pregnancy and fertility

\begin{tabular}{lc|cccc}
\hline \hline & $(1)$ & $(2)$ & $(3)$ & $(4)$ & $\begin{array}{c}(5) \\
\text { Became } \\
\text { Firth } \\
\end{array}$ \\
& $\begin{array}{c}\text { Fertility } \\
\text { Index }\end{array}$ & $\begin{array}{c}\text { Currently } \\
\text { Pregnant }\end{array}$ & $\begin{array}{c}\text { Pregnant } \\
\text { Post-Int. }\end{array}$ & $\begin{array}{c}\text { Have More } \\
\text { Kids }\end{array}$ & $\begin{array}{c}\text { Spacing } \\
(\mathrm{mo})\end{array}$ \\
\hline Husband Treated $\left(\beta_{H}\right)$ & -0.157 & -0.052 & -0.051 & -0.813 & 0.282 \\
& $(0.076)$ & $(0.029)$ & $(0.030)$ & $(0.359)$ & $(0.482)$ \\
& {$[0.041]$} & {$[0.080]$} & {$[0.096]$} & {$[0.026]$} & {$[0.559]$} \\
Wife Treated $\left(\beta_{W}\right)$ & -0.088 & -0.040 & -0.033 & -0.619 & -0.196 \\
& $(0.079)$ & $(0.031)$ & $(0.033)$ & $(0.381)$ & $(0.434)$ \\
Stratification Variables & {$[0.267]$} & {$[0.191]$} & {$[0.318]$} & {$[0.107]$} & {$[0.653]$} \\
Demographic Controls & Yes & Yes & Yes & Yes & Yes \\
\hline F-test p-value $\left(\beta_{H}=\beta_{W}\right)$ & 0.323 & 0.700 & 0.599 & 0.564 & Yes \\
\hline Mean of Control Group & 0.086 & 0.120 & 0.170 & 6.450 & 9.980 \\
Observations & 534 & 534 & 534 & 534 & 534 \\
\hline \hline
\end{tabular}

Notes: SE clustered at the meeting level in parentheses. P-values in brackets. Index variable in column 1 is the mean of all standardized variables in columns 2 and 4 and the opposite of the variable in column 5 . Stratifying control variables include if couple has children, wife over 35, wife thinks that husband wants another child later, wife thinks husband does not want another child, husband does not know of women who died at childbirth, block size, and baseline data present. Demographic control variables include wife age, husband age, wife education, husband education, number of children, age of last child born before meeting, wife is actively trying to get pregnant, baseline contraceptive use, and household weekly income.

Consistent with the patterns of changes in beliefs induced by the information treatment, when the husband is treated, we observe a $5.2 \mathrm{pp}$ decrease in the probability of the wife being pregnant at endline, a $43 \%$ reduction relative to the control group (column 2). We observe a similar pattern in the other measures of fertility. While no significant effect is observed when the wife is treated, the information treatment is associated with a large negative point estimate, and negative we cannot rule out that the effect on fertility of treating wives versus husbands is the same. ${ }^{23}$ Note that a negative fertility response that is lower in magnitude among treated women compared to treated men is consistent with the pattern of beliefs updating observed in

\footnotetext{
${ }^{22}$ To construct the birth spacing variable, we assume a due date of 4.5 month after the survey for pregnant women.

${ }^{23}$ We consider the husband's reports of pregnancy and likelihood of having other children and the same patterns arise (Appendix table A2). We did not measure past pregnancy history in the husband's survey. In Appendix figure A4, we plot the shift in the distribution of the answer to the question about the likelihood of having another child. We observe a clear positive shift in all respondent groups' answers.
} 
table 3. In particular, since only women update beliefs on risk when the wife is treated, whereas both men and women update beliefs when the husband is treated, we should expect couples in the wife treatment arm to adjust fertility outcomes less in response to the treatment than those in the husband treatment arm. Moreover, since husbands in the former arm do not change their beliefs on risk, reductions in fertility driven by changes in wives' preferences only should be accompanied by adjustments in the amount of risk compensation wives receive from husbands in the form of transfers, which we examine in the following subsection.

We build an index that comprises of the mean of the standardized fertility variables, adjusting the sign so that a decrease in fertility would be associated with a negative coefficient. ${ }^{24}$ The fertility index variable confirms what emerges from the disaggregated variables: providing maternal health cost information to husbands leads a 0.157 decline in the index variable (p-value 0.040) and providing it to wives has a non-statistically significant effect in the same direction.

Changes in realized fertility are also associated with changes in the demand for children and in beliefs over the partner's demand for children among husbands (Appendix table A3). To study self-reported demand for children, we use a wide array of measurements, summarized in an index variable that is meant to capture spouses' joint demand. Treated husbands report a negative and statistically significant shift in the demand index Appendix (table A3, column 1), which is not observed when the wife is treated. In particular, treated husbands report lower likelihood of wanting another child (column 2) and lower likelihood of believing that their wife wants another child (column 4) or that she wants more children than them (column 5). While we do not observe statistically significant effects of treatment on demand for or reported use of contraceptives at endline (Appendix table A4), use of modern contraceptives is extremely high in our sample $(68 \%)$, so changes in usage are unlikely to be detectable on the extensive margin. Point estimates on reported intensity of use are positive and suggestive of contraceptive use becoming more consistent between baseline and endline.

\subsection{Transfers and wellbeing}

Our model predicts that providing information on maternal health costs should differentially affect the transfers received by women within the marriage depending on who the recipient of the information is. In particular, we would expect that the presence of asymmetric information

\footnotetext{
${ }^{24}$ We exclude the variable that captures pregnancy after the intervention because it is very similar to the pregnancy at endline variable. Including such a variable in the index has no measurable effect on the coefficients.
} 
within the household may lead to a breakdown in contracting and a decline in transfers towards the woman when she is treated. We explore this hypothesis by examining the effects of the maternal mortality curriculum on transfers made to the wife by her husband. We focus on the husband's reports (table 5).

As expected, husbands whose wives are treated report being 13pp less likely to have made a gift to the wife in the past month (column 2), leading to a decline in the value of gift made to the wife equal to $40 \%$ of the mean of the control group (column 3), while we observe no difference in reported domestic violence (column 4). Overall, in line with prediction 3 of our model, the transfers index shifts in a negative and statistically significant way (column 1). We do not detect a positive shift of transfers in favor of women when their husbands are treated. We can rule out that the effect of treating husbands and that of treating wives is the same ( $p$-values equal to 0.001 for the index, and 0.002 in column 2 and 0.024 in column 3 for the components). ${ }^{25}$

Table 5: Transfers made to the wife

\begin{tabular}{|c|c|c|c|c|}
\hline & $\begin{array}{c}\text { (1) } \\
\text { Transfers } \\
\text { Index }\end{array}$ & $\begin{array}{l}\text { (2) } \\
\text { Any Gift in } \\
\text { past month }\end{array}$ & $\begin{array}{c}\text { (3) } \\
\text { Value } \\
\text { of gifts } \\
\text { past month }\end{array}$ & $\begin{array}{c}(4) \\
\text { Times } \\
\text { hit wife } \\
\text { last month }\end{array}$ \\
\hline \multirow{3}{*}{ Husband Treated $\left(\beta_{H}\right)$} & 0.010 & 0.017 & -9.286 & -0.023 \\
\hline & $(0.073)$ & $(0.052)$ & $(16.470)$ & $(0.038)$ \\
\hline & {$[0.888]$} & {$[0.754]$} & {$[0.574]$} & [0.553] \\
\hline \multirow[t]{3}{*}{ Wife Treated $\left(\beta_{W}\right)$} & -0.176 & -0.129 & -37.914 & -0.000 \\
\hline & $(0.068)$ & $(0.058)$ & $(14.915)$ & $(0.043)$ \\
\hline & {$[0.011]$} & {$[0.027]$} & [0.013] & {$[0.996]$} \\
\hline Stratification Variables & Yes & Yes & Yes & Yes \\
\hline Demographic Controls & Yes & Yes & Yes & Yes \\
\hline F-test p-value $\left(\beta_{H}=\beta_{W}\right)$ & 0.001 & 0.002 & 0.024 & 0.539 \\
\hline Mean of Control Group & & 0.490 & 93.830 & 0.080 \\
\hline Observations & 502 & 502 & 502 & 502 \\
\hline
\end{tabular}

Notes: SE clustered at the meeting level in parentheses. P-values in brackets. Index variable in column 1 is the mean of all standardized variables in columns 2-3 and the opposite of the variable in column 4 . Stratifying control variables include if couple has children, wife over 35, wife thinks that husband wants another child later, wife thinks husband does not want another child, husband does not know of women who died at childbirth, block size, and baseline data present. Demographic control variables include wife age, husband age, wife education, husband education, number of children, age of last child born before meeting, wife is actively trying to get pregnant, baseline contraceptive use, and household weekly income.

\footnotetext{
${ }^{25}$ Data from the wife's reports of transfers received are consistent with a reduction in transfers, but the measure is substantially more noisy and we cannot distinguish the effect of treating the husband from that of treating the wife (Appendix table A8).
} 
Finally, to investigate the effect of treatment on wellbeing, we examine four different measures of self-reported marital and personal satisfaction, together with an index variable that combines them all. We find that treated husbands report more closeness to their wife (Table 6, column 2), greater marital and sexual happiness (columns 3 and 4), but no significant change in life satisfaction. Overall, the index variable shifts positively and significantly (column 1). Other subgroups do not exhibit consistent shifts, except on the marital happiness variable, which points to a positive shift in all subgroups with the exception of treated wives.

Table 6: Spousal closeness and satisfaction

\begin{tabular}{|c|c|c|c|c|c|}
\hline & $\begin{array}{c}(1) \\
\text { Wellbeing } \\
\text { Index } \\
\end{array}$ & $\begin{array}{c}(2) \\
\text { IOS Scale } \\
\end{array}$ & $\begin{array}{c}(3) \\
\text { Happy with } \\
\text { marriage }\end{array}$ & $\begin{array}{l}(4) \\
\text { Satisfied with } \\
\text { sex life }\end{array}$ & $\begin{array}{c}(5) \\
\text { Satisfied with } \\
\text { life } \\
\end{array}$ \\
\hline \multirow[t]{3}{*}{ H Respondent $\times$ H Treated $\left(\delta_{H}^{h}\right)$} & 0.142 & 0.262 & 0.063 & 0.051 & 0.003 \\
\hline & $(0.070)$ & $(0.132)$ & $(0.037)$ & $(0.038)$ & $(0.057)$ \\
\hline & {$[0.045]$} & [0.051] & [0.088] & [0.182] & [0.953] \\
\hline \multirow{3}{*}{ H Respondent $\times \mathrm{W}$ Treated $\left(\delta_{W}^{h}\right)$} & 0.102 & 0.160 & 0.076 & 0.037 & -0.002 \\
\hline & $(0.073)$ & $(0.165)$ & $(0.038)$ & $(0.038)$ & $(0.055)$ \\
\hline & {$[0.166]$} & {$[0.335]$} & [0.050] & {$[0.334]$} & [0.969] \\
\hline \multirow{3}{*}{ W Respondent $\times \mathrm{H}$ Treated $\left(\delta_{H}^{w}\right)$} & 0.034 & 0.065 & 0.072 & -0.007 & -0.032 \\
\hline & $(0.071)$ & $(0.178)$ & $(0.038)$ & $(0.040)$ & $(0.043)$ \\
\hline & {$[0.636]$} & {$[0.715]$} & {$[0.061]$} & {$[0.867]$} & {$[0.463]$} \\
\hline \multirow[t]{3}{*}{ W Respondent $\times$ W Treated $\left(\delta_{W}^{w}\right)$} & -0.101 & -0.079 & -0.054 & -0.083 & -0.041 \\
\hline & $(0.078)$ & $(0.181)$ & $(0.046)$ & $(0.048)$ & $(0.048)$ \\
\hline & {$[0.197]$} & {$[0.663]$} & {$[0.237]$} & {$[0.088]$} & {$[0.400]$} \\
\hline Stratification Variables & Yes & Yes & Yes & Yes & Yes \\
\hline Demographic Controls & Yes & Yes & Yes & Yes & Yes \\
\hline H Respondent Interactions & Yes & Yes & Yes & Yes & Yes \\
\hline \multicolumn{6}{|l|}{ F-test p-values: } \\
\hline Direct vs. spillover effect on husband $\left(\delta_{H}^{h}=\delta_{W}^{h}\right)$ & 0.544 & 0.395 & 0.688 & 0.657 & 0.922 \\
\hline Direct vs. spillover effect on wife $\left(\delta_{W}^{w}=\delta_{H}^{w}\right)$ & 0.115 & 0.427 & 0.004 & 0.133 & 0.855 \\
\hline Symmetry of intra-hh spillover effects $\left(\delta_{H}^{w}=\delta_{W}^{h}\right)$ & 0.517 & 0.700 & 0.931 & 0.385 & 0.678 \\
\hline Direct treatment effects $\left(\delta_{H}^{h}=\delta_{W}^{w}\right)$ & 0.024 & 0.135 & 0.039 & 0.016 & 0.566 \\
\hline Mean of Control Group for $\mathrm{H}$ & & 5.630 & 0.750 & 0.790 & 0.650 \\
\hline Mean of Control Group for W & & 6.060 & 0.810 & 0.830 & 0.530 \\
\hline Observations & 1050 & 1017 & 1017 & 1017 & 1050 \\
\hline
\end{tabular}

Notes: SE clustered at the meeting level in parentheses. P-values in brackets. Index variable in column 1 is the mean of all standardized variables in columns 2-5. Stratifying control variables include if couple has children, wife over 35, wife thinks that husband wants another child later, wife thinks husband does not want another child, husband does not know of women who died at childbirth, block size, and baseline data present. Demographic control variables include wife age, husband age, wife education, husband education, number of children, age of last child born before meeting, wife is actively trying to get pregnant, baseline contraceptive use, and household weekly income. Each control variable and the constant are also interacted with a dummy for the husband being the respondent.

\subsection{Heterogeneity analysis}

Following our model, we examine how maternal health cost information generates differential responses in pregnancy by the relative risk faced by the wife and by the husband's demand for children. 


\subsubsection{By risk status at baseline}

Our model predicts that high-risk households would respond more to information about maternal health costs (prediction 5). To examine whether this is the case, we use two variables that we purposefully collected for the entire intervention sample, including the subsample for which baseline data is unavailable: a woman's age and her history of complications. We combine these two measures into a risk type dummy: a woman is defined as high risk type if the wife is higher than 35 years old (also a stratification variable) or has experienced birth/pregnancy complications before. Overall, we find that treatment effects on fertility are concentrated in the high-risk subgroup and that, when the husband is treated, we can detect a statistically significant difference between the high-risk and the low-risk subgroups (p-value 0.085, table 7). In Appendix tables A10 and A11, we show similar patterns when considering the two components of the index separately.

The reduction in transfers when the wife is treated, for both high risk and low risk women, is coherent with the theory: since only a pooling equilibrium exists, when transfers stop, they stop for all type of women. When the husband is treated, the theory predicts transfers should increase, especially for high risk women, unless the treatment has a direct effect on $\delta$, the weight the husband puts on the health of the wife. Since in Table 6 we see that that the husband appears to report more closeness to the wife, the husband may need to compensate the wife less for the spousal difference in demand for children, and this explains the decrease in tranfers.

\subsubsection{By man's demand for children at baseline}

Another set of implications of our model examine heterogeneity by men's demand for children. In table 8, we examine the heterogeneity of treatment effects on this dimension. We stratified treatment assignment on whether he wants another child within 1 year, after 1 year or not at all, and consider each group separately. In line with prediction 4 of our model, significant declines in the fertility index occur in households in which husbands want no more children and, only when the wife is treated, want children later. Households with low demand for children by the husband are more likely to reduce fertility when they receive maternal health information when the wife receives information about maternal health cost (the p-value for the test equality of treatment effects of wife's information session between a household with a man who wants a child right away and a household with a man who wants no more children is equal to 0.065). 
Table 7: Heterogeneity by relative risk

\begin{tabular}{lcc}
\hline \hline & $(1)$ & $(2)$ \\
& $\begin{array}{c}\text { Fertility } \\
\text { Index }\end{array}$ & $\begin{array}{c}\text { Transfers } \\
\text { Index }\end{array}$ \\
\hline Husband Treated $\times$ Low Risk $\left(\beta_{H}^{1}\right)$ & -0.096 & 0.080 \\
& $(0.085)$ & $(0.086)$ \\
& {$[0.264]$} & {$[0.357]$} \\
Husband Treated $\times$ High Risk $\left(\beta_{H}^{2}\right)$ & -0.317 & -0.194 \\
& $(0.114)$ & $(0.155)$ \\
& {$[0.007]$} & {$[0.213]$} \\
Wife Treated $\times$ Low Risk $\left(\beta_{W}^{1}\right)$ & -0.041 & -0.131 \\
& $(0.090)$ & $0.085)$ \\
& {$[0.646]$} & {$[0.128]$} \\
Wife Treated $\times$ High Risk $\left(\beta_{W}^{2}\right)$ & -0.214 & -0.297 \\
& $(0.123)$ & $(0.147)$ \\
Stratification Variables & {$[0.085]$} & {$[0.047]$} \\
Demographic Controls & Yes & Yes \\
\hline F-test p-value Low Risk H=W $\left(\beta_{H}^{1}=\beta_{W}^{1}\right)$ & Yes & Yes \\
F-test p-value High Risk H=W $\left(\beta_{H}^{2}=\beta_{W}^{2}\right)$ & 0.488 & 0.000 \\
F-test p-value H Low $=$ High Risk $\left(\beta_{H}^{1}=\beta_{H}^{2}\right)$ & 0.305 & 0.503 \\
F-test p-value W Low $=$ High Risk $\left(\beta_{W}^{1}=\beta_{W}^{2}\right)$ & 0.085 & 0.138 \\
\hline Observations & 5328 & 0.362 \\
\hline \hline
\end{tabular}

Notes: SE clustered at the meeting level in parentheses. P-values in brackets. Stratifying control variables include if couple has children, wife over 35, wife thinks that husband wants another child later, wife thinks husband does not want another child, husband does not know of women who died at childbirth, block size, and baseline data present. Demographic control variables include wife age, husband age, wife education, husband education, number of children, age of last child born before meeting, wife is actively trying to get pregnant, baseline contraceptive use, and household weekly income.

Moreover, within the subsample in which the husband wants a child as soon as possible, providing information to wives has no effect on fertility. The p-value of the test that compares the effect of treating husbands to the effects of treating wives within this subgroup is equal to 0.111 . In the subgroup in which the husband wants another child but not as soon as possible, the p-value is equal to 0.116 . Only in the subgroup in which the husband want no more children, it appears that treating the wife and treating her husband has the same effect on the fertility index (p-value equal to 0.809$)$.

To study the diffusion of information within the household and hence understand the roots of these fertility effects, we focus on untreated respondents and examine how their beliefs shift in response to their spouse's treatment status (table 9). Using the index in the ladder scale 
Table 8: Heterogeneity of effects on indices by the husband's demand for children

\begin{tabular}{|c|c|c|}
\hline & $\begin{array}{c}\text { (1) } \\
\text { Fertility Index }\end{array}$ & $\begin{array}{c}(2) \\
\text { Transfers Index }\end{array}$ \\
\hline \multirow{3}{*}{ Husband Treated $\times$ H Wants Kids Now $\left(\beta_{H}^{1}\right)$} & -0.105 & 0.093 \\
\hline & $(0.166)$ & $(0.257)$ \\
\hline & [0.531] & {$[0.719]$} \\
\hline \multirow{3}{*}{ Husband Treated $\times \mathrm{H}$ Wants Kids Later $\left(\beta_{H}^{2}\right)$} & -0.244 & 0.124 \\
\hline & $(0.149)$ & $(0.236)$ \\
\hline & {$[0.104]$} & {$[0.601]$} \\
\hline \multirow[t]{3}{*}{ Husband Treated $\times \mathrm{H}$ Wants Kids Never $\left(\beta_{H}^{3}\right)$} & -0.262 & -0.066 \\
\hline & $(0.108)$ & $(0.117)$ \\
\hline & [0.018] & {$[0.574]$} \\
\hline \multirow[t]{3}{*}{ Wife Treated $\times$ H Wants Kids Now $\left(\beta_{W}^{1}\right)$} & 0.168 & -0.210 \\
\hline & $(0.188)$ & $(0.178)$ \\
\hline & {$[0.374]$} & {$[0.241]$} \\
\hline \multirow[t]{3}{*}{ Wife Treated $\times$ H Wants Kids Later $\left(\beta_{W}^{2}\right)$} & -0.070 & -0.061 \\
\hline & $(0.167)$ & $(0.205)$ \\
\hline & {$[0.677]$} & {$[0.767]$} \\
\hline \multirow[t]{3}{*}{ Wife Treated $\times$ H Wants Kids Never $\left(\beta_{W}^{3}\right)$} & -0.285 & -0.230 \\
\hline & $(0.117)$ & $(0.104)$ \\
\hline & {$[0.017]$} & {$[0.029]$} \\
\hline Stratification Variables & Yes & Yes \\
\hline Demographic Controls & Yes & Yes \\
\hline F-test $\mathrm{p}$-value Now $\mathrm{H}=\mathrm{W}\left(\beta_{H}^{1}=\beta_{W}^{1}\right)$ & 0.111 & 0.255 \\
\hline F-test p-value Later $\mathrm{H}=\mathrm{W}\left(\beta_{H}^{2}=\beta_{W}^{2}\right)$ & 0.116 & 0.205 \\
\hline F-test p-value Never $\mathrm{H}=\mathrm{W}\left(\beta_{H}^{3}=\beta_{W}^{3}\right)$ & 0.809 & 0.038 \\
\hline $\mathrm{F}$ test $\mathrm{p}$-value $\mathrm{H}$ Now $=\operatorname{Never}\left(\beta_{H}^{1}=\beta_{H}^{3}\right)$ & 0.474 & 0.607 \\
\hline F test $\mathrm{p}$-value $\mathrm{W}$ Now $=\operatorname{Never}\left(\beta_{W}^{1}=\beta_{W}^{3}\right)$ & 0.065 & 0.923 \\
\hline Observations & 440 & 410 \\
\hline
\end{tabular}

Notes: SE clustered at the meeting level in parentheses. P-values in brackets. Stratifying control variables include if couple has children, wife over 35, wife thinks that husband wants another child later, wife thinks husband does not want another child, husband does not know of women who died at childbirth, block size, and baseline data present. Demographic control variables include wife age, husband age, wife education, husband education, number of children, age of last child born before meeting, wife is actively trying to get pregnant, baseline contraceptive use, and household weekly income.

questions as dependent variable, we find that the subgroup of households in which the husbands wants a child as soon as possible drives the asymmetry in the spillover effect of information within the household: in this subgroup, we can rule out that the spillover between spouses are the same (p-value 0.045). Also, it is husbands who want a child as soon as possible whose beliefs exhibit the smallest (negative) response to the wife's treatment status (p-value of comparison with men who want no more children is 0.116 ), supporting the hypothesis of a backlash. 
As predicted, the heterogeneity effects with respect to transfers mirrors the effects for fertility when $\alpha^{H}$ is high: even though the effects are not significant, transfers increase only when the husband is treated. When $\alpha^{H}$ is low, transfers significantly decrease when the wife is treated, as predicted by the theory; when the husband is treated, the effect is ambiguous, as transfers are expected to increase when the husband wants more children then the wife, and decrease when he wants less children then her.

\subsection{Discussion and alternative interpretations}

The empirical findings that we have described indicate that information about maternal health is relevant to households making fertility decisions. When men participate in an information session about maternal health risk, we observe an increase in awareness both in his answers and, when risk factors are concerned, in their wives' answers. When women participate in similar sessions, they also exhibit greater awareness - but their husbands, if anything, exhibit lower perceptions of maternal health risk. We interpret this finding as the result of a barrier to communication from women to men on maternal health, due to a conflict of interest often present in the household when fertility decisions are made. This conflict may arise from different preferences, from different incidence of the costs of maternal health, or from women's desire to maximize the amount of transfers they receive. As a result of the asymmetric information friction, we observe a breakdown of transfers made from the husband to the wife after treatment, when it is the woman who receives the maternal health information, but not when it is the man.

The presence of a barrier to communication within the household on maternal health risk has material implications for how information about this subject affects families. While the information treatment has similar significant effects on fertility decline when it is provided to women as when it is provided to men, it leads to a reduction in the transfers from husband to wife only when provided to women. According to our model, this happens because the transfers that are optimal given the (limited) information the husband has are not incentive compatible for the wife, given the information she has after the intervention. Moreover, providing information to women only reduces fertility when the husband already wants to stop having additional children.

Based on our findings, a natural question is whether similar asymmetric informational spillovers in the household may simply arise more generically from men's lower likelihood to listen to women, even when incentives are perfectly aligned. While this explanation is com- 
Table 9: Symmetry of knowledge spillovers index on untreated spouses by the husband's demand

\begin{tabular}{|c|c|}
\hline & $\begin{array}{c}\text { (1) } \\
\text { Beliefs Index spillover }\end{array}$ \\
\hline Wife respondent: Husband Treated $\times$ H Wants Kids Now $\left(\delta_{H}^{w 1}\right)$ & $\begin{array}{c}0.200 \\
(0.142) \\
{[0.162]}\end{array}$ \\
\hline Wife respondent: Husband Treated $\times$ H Wants Kids Later $\left(\delta_{H}^{w 2}\right)$ & $\begin{array}{c}0.078 \\
(0.101) \\
{[0.440]}\end{array}$ \\
\hline Wife respondent: Husband Treated $\times \mathrm{H}$ Wants Kids Never $\left(\delta_{H}^{w 3}\right)$ & $\begin{array}{c}-0.048 \\
(0.074) \\
{[0.517]}\end{array}$ \\
\hline Husband respondent: Wife Treated $\times$ H Wants Kids Now $\left(\delta_{W}^{h 1}\right)$ & $\begin{array}{c}-0.214 \\
(0.134) \\
{[0.115]}\end{array}$ \\
\hline Husband respondent: Wife Treated $\times$ H Wants Kids Later $\left(\delta_{W}^{h 2}\right)$ & $\begin{array}{c}0.002 \\
(0.126) \\
{[0.985]}\end{array}$ \\
\hline Husband respondent: Wife Treated $\times$ H Wants Kids Never $\left(\delta_{W}^{h 3}\right)$ & $\begin{array}{c}-0.072 \\
(0.077) \\
{[0.356]}\end{array}$ \\
\hline Stratification Variables & Yes \\
\hline Demographic Controls & Yes \\
\hline H Respondent Interactions & Yes \\
\hline F-test $\mathrm{p}$-value Now $\mathrm{H}=\mathrm{W}\left(\delta_{H}^{w 1}=\delta_{W}^{h 1}\right)$ & 0.045 \\
\hline F-test $\mathrm{p}$-value Later $\mathrm{H}=\mathrm{W}\left(\delta_{H}^{w 2}=\delta_{W}^{h 2}\right)$ & 0.622 \\
\hline F-test p-value Never $\mathrm{H}=\mathrm{W}\left(\delta_{H}^{w 3}=\delta_{W}^{h 3}\right)$ & 0.831 \\
\hline F test $\mathrm{p}$-value $\mathrm{H}$ Now $=$ Never $\left(\delta_{H}^{w 1}=\delta_{H}^{w 3}\right)$ & 0.116 \\
\hline F test $\mathrm{p}$-value $\mathrm{W}$ Now $=$ Never $\left(\delta_{W}^{h 1}=\delta_{W}^{h 3}\right)$ & 0.366 \\
\hline Observations & 560 \\
\hline
\end{tabular}

Notes: SE clustered at the meeting level in parentheses. P-values in brackets. Index variable in column 1 is the mean of all standardized variables in columns 2-3 and the opposite of the variable in column 4 . Stratifying control variables include if couple has children, wife over 35, wife thinks that husband wants another child later, wife thinks husband does not want another child, husband does not know of women who died at childbirth, block size, and baseline data present. Demographic control variables include wife age, husband age, wife education, husband education, number of children, age of last child born before meeting, wife is actively trying to get pregnant, baseline contraceptive use, and household weekly income.

plementary to ours and also highlights the importance of optimally targeting the provision of information within the household, it could not explain, by itself, some of our empirical findings. In particular, assuming that husbands simply discount information provided by women would not explain why transfers to the wife decrease after she is treated, nor the patterns of 
heterogeneity by the men's demand for children that we observe in the data, which indicate that conflict of interest may play a role in how information spreads within the household. It is also worth emphasizing that each group workshop featured a male and female facilitator. Yet, we did not observe lower interest or engagement arise from the part of the sessions that were conveyed by women. For example, according to our scripts, in each session, it was the female motivator who discussed low birth spacing as a risk factor. At followup, treated men are more likely than the control group to correctly identify it as such (Appendix table A5 column 4), showing that they incorporate the material covered by the female motivator in their answers.

\subsection{Robustness checks}

In the main specification, we have selected a small set of controls, that are held fixed in all of the analysis. To further limit the discretion in the choice of control, we perform post double selection LASSO to select control variables (Belloni, Chernozhukov and Hansen, 2014). The results of this exercise for all of our main dependent variables are reported in Appendix tables A12 and A13. The qualitative and quantitative implications of our analysis are broadly unchanged, but coefficients become more precise in some instances.

\section{Concluding remarks}

In an intervention in which men or women in Lusaka (Zambia) receive information about maternal health risk, we find that the intervention has different effects on participants' beliefs and on household outcomes depending on who receives the information. In particular, treated men and their wives update their beliefs over the risk factors of maternal health complications in response to the intervention. The same happens to treated women, but not to their husband. When men are treated, communication about reproductive health, self-reported spousal closeness and marital satisfaction all increase. When women are treated, we see no change in these outcomes, and transfers in their favor from the husband decline. Moreover, while pregnancy declines over the following year among all couples, only when women are treated is the fertility reduction accompanied by a significant decline in material transfers from husbands to wives.

These findings are consistent with a model in which the existence of conflict of interest over fertility outcomes within the household can prevent women from effectively communicating about 
maternal health risk with their partner. Such a conflict may arise from different preferences, from different incidence of the costs of maternal health, or from women's desire to maximize the amount of transfers they receive. The model can also explain what we find in our baseline data: women, in general, have more accurate knowledge of the risk factors for maternal mortality compared to men, even within the same household. Because of such conflict of interest, as well as other barriers to communication such as the stigma associated with maternal mortality in many parts of Africa, women face a personal cost in protecting their health by reducing or spacing births. Hence, there may be significant gains to interventions that target men as the recipients of maternal health information campaigns, which are currently rare and typically take place after conception (Tokhi et al., 2018).

In a domain where separate spheres are important, in that women are more likely to learn about a phenomenon than men (or viceversa), it may be difficult for the information to spread within the household, and hence public intervention may be particularly important. Such domains may arise not only with maternal health, but also child health (Björkman Nyqvist and Jayachandran, 2017), investments in children's human capital, and other important household decisions whose costs or benefits, in many contexts, are observed or borne primarily by one household member, but influence the decision making of the entire household.

A simple policy intervention is to educate couples together. While our model would predict that similar updating would occur from educating men alone versus a husband and a wife together (because knowledge provided to men spreads more easily to the wife), we cannot assess how much of the effect we see is due to men learning this information on maternal health information together with other men around them, rather than other couples around them (or solely with their wife). We leave this to future research.

More generally, this paper reveals how gender differences can be exacerbated by information frictions, creating greater polarization and enabling significant inefficiencies to arise. Overcoming the information frictions breaks this cycle. In our setting, treating men directly leads to updating of information for both spouses, a greater alignment in fertility demand, reduced fertility and greater marital satisfaction. In a world in which there is often pressure from donor organizations for sub-Saharan African country governments, in particular, to promote family planning, our paper describes a "family-centric" approach that does not sacrifice intra-household happiness to advance health policy goals. 


\section{References}

Albanesi, Stefania, and Claudia Olivetti. 2014. "Maternal health and the baby boom." Quantitative Economics, 5(2): 225-269.

Apedo-Amah, Marie Christine, Habiba Djebbari, and Roberta Ziparo. 2020. "Gender, Information and the Efficiency of Household Production Decisions: An Experiment in Rural Togo." Institute of Labor Economics (IZA) IZA Discussion Papers 12948.

Ashraf, Nava. 2009. "Spousal control and intra-household decision making: An experimental study in the Philippines." The American Economic Review, 1245-1277.

Ashraf, Nava, Erica Field, and Jean Lee. 2014. "Household bargaining and excess fertility: an experimental study in Zambia." American Economic Review, 104(7): 2210-37.

Ashraf, Nava, Erica Field, Giuditta Rusconi, Alessandra Voena, and Roberta Ziparo. 2017. "Traditional beliefs and learning about maternal risk in Zambia." American Economic Review, 107(5): 511-515.

Attanasio, Orazio, and Valerie Lechene. 2002. "Tests of the income pooling in household decisions." Review of economic dynamics, 5(4): 720-748.

Banda, Pamela C. 2015. "Status of maternal mortality in Zambia: use of routine data." African Population Studies, 29(2).

Baseler, Travis. 2020. "Hidden Income and the Perceived Returns to Migration: Experimental Evidence from Kenya." Available at SSRN 3534715.

Bauer, Gerrit, and Thorsten Kneip. 2012. "Fertility From a Couple Perspective: A Test of Competing Decision Rules on Proceptive Behaviour." European Sociological Review, $29(3): 535-548$.

Belloni, Alexandre, Victor Chernozhukov, and Christian Hansen. 2014. "Inference on treatment effects after selection among high-dimensional controls." The Review of Economic Studies, 81(2): 608-650.

Bennett, Daniel, Asjad Naqvi, and Wolf-Peter Schmidt. 2018. "Learning, hygiene and traditional medicine." The Economic Journal, 128(612): F545-F574.

Björkman Nyqvist, Martina, and Seema Jayachandran. 2017. "Mothers Care More, But Fathers Decide: Educating Parents about Child Health in Uganda." American Economic Review, 107(5): 496-500.

Blanc, Ann K. 2001. "The effect of power in sexual relationships on sexual and reproductive health: an examination of the evidence." Studies in family planning, 32(3): 189-213.

Bond, Virginia, and Paul Dover. 1997. "Men, women and the trouble with condoms: problems associated with condom use by migrant workers in rural Zambia." Health transition review, 377-391.

Bourguignon, François, Martin Browning, Pierre-Andre Chiappori, and Valerie Lechene. 1993. "Intra Household Allocation of Consumption: A Model and Some Evidence from French Data." Annales d'Économie et de Statistique, , (29): 137-156. 
Brehm, Uta, and Norbert F. Schneider. 2019. "Towards a Comprehensive Understanding of Fertility:The Model of Dyadic Pathways." Comparative Population Studies, 44.

Cai, Hongbin, and Joseph Tao-Yi Wang. 2006. "Overcommunication in strategic information transmission games." Games and Economic Behavior, 56(1): 7 - 36.

Central Statistical Office. 2014. "Central Statistical Office (CSO), Ministry of Health (MOH), and ICF International."

Chen, Joyce J. 2013. "Identifying Non-Cooperative Behavior Among Spouses: Child Outcomes in Migrant-Sending Households." Journal of Development Economics, 100(1): 1-18.

Chen, Y., N. Kartik, and J. Sobel. 2007. "On the Robustness of Informative Cheap Talk ."

Chiappori, Pierre-Andrè. 1992. "Collective labor supply and welfare." Journal of Political Economy, 437-467.

Cho, In-Koo, and David M. Kreps. 1987. "Signaling Games and Stable Equilibria." The Quarterly Journal of Economics, 102(2): 179-221.

Conlon, John J, Malavika Mani, Gautam Rao, Matthew Ridley, and Frank Schilbach. 2021. "Learning in the Household." NBER Working Paper, , (w28844).

Crawford, Vincent. 1998. "A survey of experiments on communication via cheap talk." Journal of Economic theory, 78(2): 286-298.

Crawford, Vincent P. 2019. "Experiments on cognition, communication, coordination, and cooperation in relationships."

Crawford, Vincent P, and Joel Sobel. 1982. "Strategic information transmission." Econometrica: Journal of the Econometric Society, 1431-1451.

de Laat, Joost. 2005. "Moral Hazard and Costly Monitoring: The Case of Split Migrants in Kenya." Mimeo, Brown University.

Delavande, Adeline, and Hans-Peter Kohler. 2016. "HIV/AIDS-related expectations and risky sexual behaviour in Malawi." The Review of Economic Studies, 83(1): 118-164.

De Paula, Áureo, Gil Shapira, and Petra E Todd. 2014. "How beliefs about HIV status affect risky behaviors: Evidence from Malawi." Journal of Applied Econometrics, 29(6): 944964.

DeRose, Laurie F, F Nii-Amoo Dodoo, Alex C Ezeh, and Tom O Owuor. 2004. "Does discussion of family planning improve knowledge of partner's attitude toward contraceptives?" International family planning perspectives, 87-93.

Dickhaut, John W., Kevin A. McCabe, and Arijit Mukherji. 1995. "An Experimental Study of Strategic Information Transmission." Economic Theory, 6(3): 389-403.

Dickson, Eric, Catherine Hafer, and Dimitri Landa. 2008. "Cognition and Strategy: A Deliberation Experiment." Journal of Politics, 70: 974-989. 
Dizon-Ross, Rebecca. 2019. "Parents' beliefs about their children's academic ability: Implications for educational investments." American Economic Review, 109(8): 2728-65.

Dodoo, F Nii-Amoo. 1998. "Men matter: additive and interactive gendered preferences and reproductive behavior in Kenya." Demography, 35(2): 229-242.

Doepke, Matthias, and Fabian Kindermann. 2019. "Bargaining over Babies: Theory, Evidence, and Policy Implications." American Economic Review, 109(9): 3264-3306.

Duflo, Esther. 2003. "Grandmothers and granddaughters: old-age pensions and intrahousehold allocation in South Africa." The World Bank Economic Review, 17(1): 1-25.

Dupas, Pascaline. 2011. "Do Teenagers Respond to HIV Risk Information? Evidence from a Field Experiment in Kenya." American Economic Journal: Applied Economics, 3(1): 1-34.

Ezeh, Alex Chika. 1993. "The influence of spouses over each other's contraceptive attitudes in Ghana." Studies in family planning, 163-174.

Fernandez, Raquel, and Alessandra Fogli. 2009. "Culture: An empirical investigation of beliefs, work, and fertility." American economic journal: Macroeconomics, 1(1): 146-77.

Fisek, Nusret H., and K. Sumbuloglu. 1978. "The effects of husband and wife education on family planning in rural Turkey." Studies in Family Planning, 9.

Freedman, Ronald, and John Y. Takeshita. 1969. Family Planning in Taiwan: An Experiment in Social Change. Princeton University Press.

Garenne, Michel, Khadidiatou Mbaye, Mohamed D Bah, and Paul Correa. 1997. "Risk factors for maternal mortality: a case-control study in Dakar hospitals (Senegal)." African Journal of Reproductive Health, 14-24.

Geller, Stacie E, Abigail R Koch, Caitlin E Garland, E Jane MacDonald, Francesca Storey, and Beverley Lawton. 2018. "A global view of severe maternal morbidity: moving beyond maternal mortality." Reproductive health, 15(1): 98.

Gennaro, Susan, Lennie A Kamwendo, Ellen Mbweza, and Rose Kershbaumer. 1998. "Childbearing in Malawi, Africa." Journal of Obstetric, Gynecologic, \& Neonatal Nursing, 27(2): 191-196.

Goldenberg, Robert L, Sarah Saleem, Sumera Ali, Janet L Moore, Adrien Lokangako, Antoinette Tshefu, Musaku Mwenechanya, Elwyn Chomba, Ana Garces, Lester Figueroa, et al. 2017. "Maternal near miss in low-resource areas." International Journal of Gynecology \& Obstetrics, 138(3): 347-355.

Gottert, Ann, Clare Barrington, Heath Luz McNaughton-Reyes, Suzanne Maman, Catherine MacPhail, Sheri A Lippman, Kathleen Kahn, Rhian Twine, and Audrey Pettifor. 2018. "Gender norms, gender role conflict/stress and HIV risk behaviors among men in Mpumalanga, South Africa." AIDS and Behavior, 22(6): 1858-1869.

Jensen, Rober. 2010. "The (perceived) returns to education and the demand for schooling." The Quarterly Journal of Economics, 125(2): 515. 
Lundberg, Shelly, and Robert A. Pollak. 1996. "Bargaining and distribution in marriage." The Journal of Economic Perspectives, 10(4): 139-158.

Lundberg, Shelly J, Robert A Pollak, and Terence J Wales. 1997. "Do husbands and wives pool their resources? Evidence from the United Kingdom child benefit." Journal of Human resources, 463-480.

Mailath, George J. 1987. "Incentive compatibility in signaling games with a continuum of types." Econometrica: Journal of the Econometric Society, 1349-1365.

McCarthy, Aine Seitz. 2019. "Intimate partner violence and family planning decisions: Experimental evidence from rural Tanzania." World Development, 114: 156-174.

Miller, Grant, Áureo De Paula, and Christine Valente. 2020. "Subjective Expectations and Demand for Contraception." National Bureau of Economic Research.

Miller, Warren B., Lawrence J. Severy, and David J. Pasta. 2004. "A Framework for Modelling Fertility Motivation in Couples." Population Studies, 58(2): 193-205.

Nsemukila, Buleti G, Dean S Phiri, Hady M Diallo, Sekelani S Banda, Wendy K Benaya, and Naomi Kitahara. 1999. A Study of Factors Associated with Maternal Mortality in Zambia, 1998. Zambia Ministry of Health.

Phiri, Selia N, Knut Fylkesnes, Ana L Ruano, and Karen M Moland. 2014. "'Born before arrival': user and provider perspectives on health facility childbirths in Kapiri Mposhi district, Zambia." BMC pregnancy and childbirth, 14(1): 1.

Pulerwitz, Julie, Annie Michaelis, Ravi Verma, and Ellen Weiss. 2010. "Addressing gender dynamics and engaging men in HIV programs: lessons learned from Horizons research." Public health reports, 125(2): 282-292.

Rasul, Imran. 2008. "Household bargaining over fertility: Theory and evidence from malaysia." Journal of Development Economics, 86(2): 215-241.

Rosenzweig, Mark R, and T Paul Schultz. 1982. "Child mortality and fertility in Colombia: individual and community effects." Health policy and education, 2(3-4): 305-348.

Rossi, Pauline. 2019. "Strategic Choices in Polygamous Households: Theory and Evidence from Senegal." Review of Economic Studies, 86(3): 1332-1370.

Shattuck, Dominick, Brad Kerner, Kate Gilles, Miriam Hartmann, Thokozani Ng'ombe, and Greg Guest. 2011. "Encouraging Contraceptive Uptake by Motivating Men to Communicate About Family Planning: The Malawi Male Motivator Project." American Journal of Public Health, 101(6): 1089.

Stein, Petra, Sebastian Willen, and Monika Pavetic. 2014. "Couples' fertility decisionmaking." Demographic Research, S16(63): 1697-1732.

Stern, Steven, and Leora Friedberg. 2010. "Marriage, Divorce, and Asymmetric Information." Virginia Economics Online Papers, 385. 